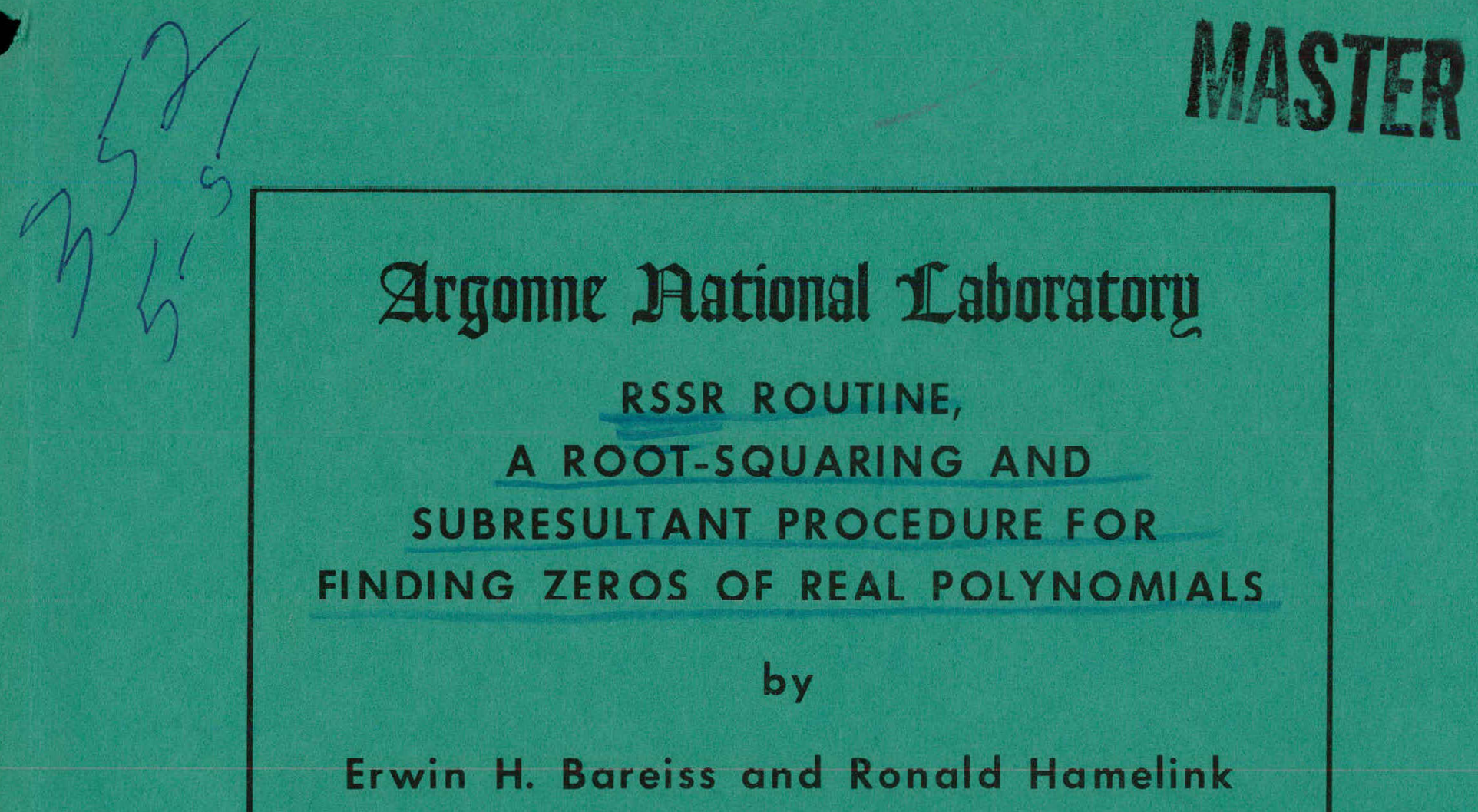




\section{DISCLAIMER}

This report was prepared as an account of work sponsored by an agency of the United States Government. Neither the United States Government nor any agency Thereof, nor any of their employees, makes any warranty, express or implied, or assumes any legal liability or responsibility for the accuracy, completeness, or usefulness of any information, apparatus, product, or process disclosed, or represents that its use would not infringe privately owned rights. Reference herein to any specific commercial product, process, or service by trade name, trademark, manufacturer, or otherwise does not necessarily constitute or imply its endorsement, recommendation, or favoring by the United States Government or any agency thereof. The views and opinions of authors expressed herein do not necessarily state or reflect those of the United States Government or any agency thereof. 


\section{DISCLAIMER}

Portions of this document may be illegible in electronic image products. Images are produced from the best available original document. 


\section{LEGAL NOTICE}

This report was prepared as an account of Government sponsored work. Neither the United States, nor the Commission, nor any person acting on behalf of the Commission:

A. Makes any warranty or representation, expressed or implied, with respect to the accuracy, completeness, or usefulness of the information contained in this report. or that the use of any information, apparatus, method, or process disclosed in this report may not infringe privately owned rights; or

B. Assumes any liabilities with respect to the use of, or for damages resulting from the use of any information, apparatus, method, or process disclosed in this report.

As used in the above, "person acting on behalf of the Commission" includes any employee or contractor of the Commission, or employee of such contractor, to the extent that such employee or contractor of the Commission, or employee of such contractor prepares, disseminates, or provides access to, any information pursuant to his employment or contract with the Commission, or his employment with such contractor.

Printed in USA. Price $\$ 3.00$. Available from the Clearinghouse for Federal Scientific and Technical Information, National Bureau of Standards,

U. S. Department of Commerce, Springfield, Virginia 
Thls report was prepared as an account of Government sponsored work. Neither the United States, nor the Commission, nor any person acting on behalf of the Commission:

A. Makes any warranty or representation, expressed or implied, with respect to the accuracy, completeness, or usefulness of the fnformation contalned in this report, or that the use of any information, apparatus, method, or process dlsclosed in this report may not infringe privately ouned rights; or

B. Assumes any liabllites with respect to the use of, or for damages resulting from the use of any information, apparatus, method, or process disclosed in this report.

As ued in the above "peroon actne on behalf of the Commanployee used ln the above. "peraon acthe on behall of the com ployee or contractor of the comb such employee or contractor of the Commission, or employee of such contractor prepares, disseminates, or provldes access to, any information pursuant to hls employment or contrac with the Commission, or his employment with such contractor.

\section{ARGONNE NATIONAL LABORATORY \\ 9700 South Cass Avenue Argonne, Illinois 60440}

\section{ANL-6987}

Mathematics and Computers (TID-4500)

AEC Research and

Development Report

RSSR ROUTINE,

A ROOT-SQUARING AND SUBRESULTANT PROCEDUंRE

FOR FINDING ZEROS OF REAL POLYNOMIALS

by

Erwin H. Bareiss

Applied Mathematics Division

Argonne National Laboratory

H.C. $\$ 3.00 ; M N .25$

\author{
and
Ronald Hamelink
Michigan State University
Michigan State University
East Lansing, Michigan

October 1965

RELEASED ROR ANNOUNCEMENT

IN NUCLEAR SCIENCE ABSTRACTS

\footnotetext{
Operated by The University of Chicago under

Contract W-31-109-eng-38

with the

U. S. Atomic Energy Commission
} 


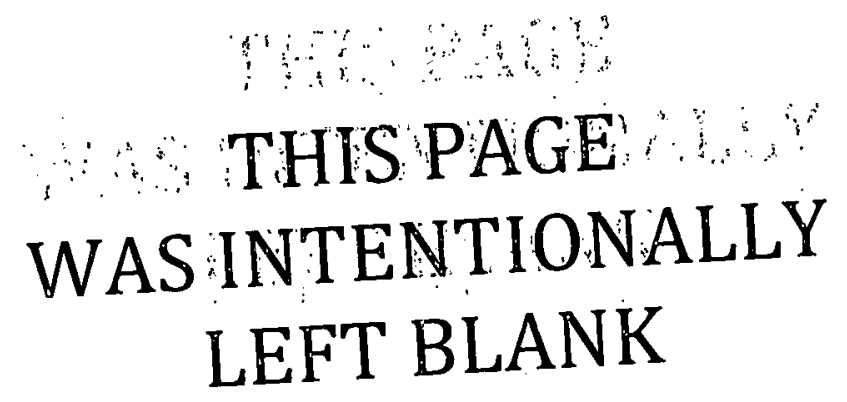


TABLE OF CONTENTS

$\underline{\text { Page }}$

ABSTRACT .......................... 5

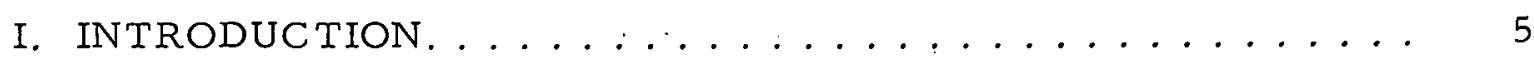

A. Motivation. .................... 5

B. The Basic Idea of the Resultant Procedures ......... 5

C. Outline ...................... 7

D. Notation ........................ 7

II. DESCRIPTION OF THE MFTHOD . . . . . . . . . .

III. DESCRIPTION OF THE RSSR CODE ........... 11

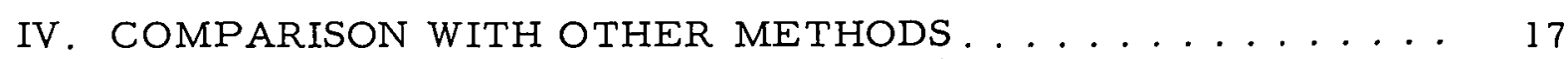
APPENDIXES

A: Numerical Examples. . . . . . . . . . . . . . . . . . 19

1. Some General Remarks. . . . . . . . . . . . . . . 19

2. Polynomials Solved .................. 19

B. FORTRAN Statements................. 28

1. FORTRAN II Statements of the RSSR Routine as Coded for the IBM-704 Computer. . . . . . . . . . 28

2. FORTRAN 63 Statements of the RSSR Routine as Coded for the CDC-3600 Computer............. 49

C: Operating Instructions. ............... 71

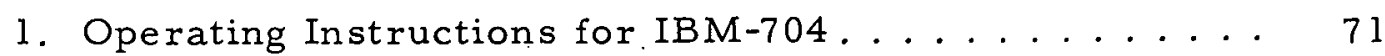

2. Operating Instructions for CDC-3600 . . . . . . 73

ACKNOWLEDGMENTS . . . . . . . . . . . . . . . . . 74

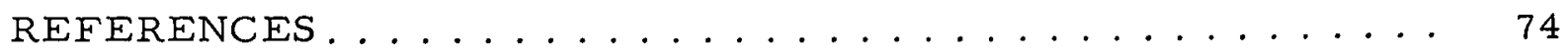




\section{LIST OF· FIGURES}

No.

Title

Page

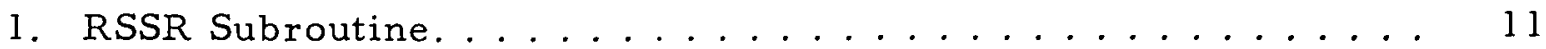

2. Finding of Moduli of Roots and Real Roots . . . . . . . . . 12

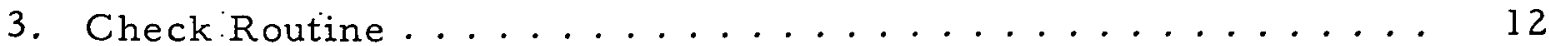

4. Flow Chart for Finding the Reduced Subresultant Polynomial.. 


\title{
RSSR ROUTINE, \\ A ROOT-SQUARING AND SUBRESULTANT PROCEDURE FOR FINDING ZEROS OF REAL POLYNOMIALS
}

by

Erwin H. Bareiss and Ronald Hamelink

\begin{abstract}
This report describes the theoretical background of the RSSR Routine, a program for finding simultaneously all roots of a real polynomial equation. Codes for the IBM-704 and CDC-3600 are described, including complete listings of FORTRAN statements. These codes are designed to solve polynomials of degree up to order 20 to 30 , but dimensioning allows the possible solution of polynomial equations of degree up to 50. A set of sample problems is presented which may also serve to test other root-finding routines.
\end{abstract}

\section{INTRODUCTION}

\section{A. Motivation}

In 1957, one of the authors conceived the concept of the "Resultant Procedures."1,2 The corresponding code for the IBM-704 proved very successful and has not undergone any changes in the past 7 years. With the acquisition by the Applied Mathematics Division of a new computer, the CDC-3600, it was felt the code should be rewritten and possibly improved. Based on the performance of the code, it was felt that a less conservative approach could be tolerated, and therefore and even faster code designed. This was indeed accomplished. The idea was to make the code very fast for frequently encountered distributions of the zeros of polynomials as they occurred in the past, and not to worry too much over other types, such as multiple complex zeros, as long as the routine was able to obtain them all.

B. The Basic Idea of the Resultant Procedures

Assume that a real polynomial,

$$
P_{n}(x)=\sum_{i=0}^{n} a_{i} x^{n-i}
$$


and a quadratic factor

$$
Q(p, q)=x^{2}+p x+q
$$

are given. Then

$$
P_{n}=Q P_{n-2}+R_{1} x+R
$$

where

$$
P_{n-2}=\sum_{i=0}^{n-2} b_{i} x^{n-2-i}
$$

is a polynomial $P_{n-2}(x)$ of order $n-2$. The remainder terms $R$ and $R_{1}$ are functions of $p$ and $q$ and can be shown to be related to the resultant and the subresultant [e.g., $R_{1}=R^{\prime}(p, q)$ ] of Reference 1 . In order that $Q$ be a factor of $P_{n}(x)$, both $R$ and $R_{1}$ must vanish. This can be achieved in different ways. In applying the gradient method or Newton-Raphson method simultaneously to

$$
R(p, q)=0
$$

and

$$
R_{1}(p, q)=0
$$

one obtains the Hitchcock-Bairstow iteration (Reference 5, page 472). Other procedures are due to Lin, Friedman, and others (Reference 1, page 381 ; Reference 4, page 468). In all methods, the purpose of finding a quadratic factor, say $Q(p, q)$, is to determine pairs of complex conjugate roots of a real polynomial, thus avoiding arithmetic with complex numbers. The idea of the resultant procedures as discussed in detail in Reference 1 is to first find the real $q$ by a different method, and then to solve either

$$
R(p, q)=0
$$

or

$$
\text { Resultant }=0 \text { (Resultant Procedure) }
$$

or

$$
R_{1}(p, q)=0 \text { (Subresultant Procedure) }
$$

with q known. Referring again to Reference 1 or 2, it can be shown that $R(p, q)$ with known real $q$ is a real polynomial of order $n$ in $p$, and $R_{1}(p, q)$ with known real $q$ is a real polynomial of order $n-1$. If $Q(p, q)$ is a 
quadratic factor of $P_{n}(x)$ such that its zeros are $\alpha$ and $\bar{\alpha}$, then $q=\alpha \bar{\alpha}$. If $\alpha$ has modulus $\rho$, then

$$
q=\rho^{2} \text {. }
$$

As explained in Reference 1 , the modules to any zeros of a real polynomial can be found efficiently and accurately by a modification of the well-known Graeffe root-squaring method. It is further shown that the set of real roots $\mathrm{p}_{i}$ of $\mathrm{R}\left(\mathrm{p}, \rho^{2}\right)=0$ and $\mathrm{R}_{1}\left(\mathrm{p}, \rho^{2}\right)=0$ contain those $\mathrm{p}$ that make $\mathrm{Q}\left(\mathrm{p}, \rho^{2}\right)$ a factor of $P_{n}(x)$. It is sufficient either to solve $R\left(p, \rho^{2}\right)=0$; or to find $p$ such that the resultant vanishes, which leads to the resultant procedure as worked out in detail in Reference l; or to solve $R_{1}\left(p, \rho^{2}\right)=0$, which leads to a subresultant procedure as briefly discussed in Reference 1. Since in either case we have reduced the problem to finding only moduli of roots, we can use the modified root-squaring method mentioned above again as a subroutine. From the quadratic equation $Q\left(p_{i}, \rho^{2}\right)=0$, the corresponding complex zeros $\alpha$ and $\bar{\alpha}$ are easily found.

By combining the $R(p, q)$ and $R_{1}(p, q)$, it is possible by elementary elimination to reduce the order in $p$ of $R(p, q)$ from $n$ to $n-2$ (see Reference 6), and the order in $p$ of the subresultant $R_{1}(p, q)$ from $n-1$ to $n-3$. The code described in this paper uses the reduced subresultant.

\section{Outline}

In the next sections, we discuss the general plan of the RSSR code, which has been in successful operation since summer 1963, and motivate some of the refinements. Then we demonstrate by a simple example that the Graeffe method as usually known exhibits a numerical stability behavior less favorable than the resultant procedures.

In Appendix A, a selection of problems is discussed that may also be used to test the efficiency or reliability of other root-finding routines.

In Appendix B, we present FORTRAN listings of the present RSSR code.

In. Appendix $C$, we present the operating instructions for the IBM-704 and CDC- 3600 .

D. Notation

The following symbols will be used in whal follows:

$M=$ number of root-squaring iterations; 
$P(x)=\sum_{i=0}^{n} a_{i} x^{n-i}$, polynomial with real coefficients $a_{i}$ and zeros $\left(\alpha_{j}\right)_{t}$

$P(m)(x)=\sum_{i=0}^{n} a_{i}^{(m)} x^{n-i}$, polynomial with roots $\left(\alpha_{j}^{2 m}\right)_{t} ;$

$-\mathrm{p}=\alpha+\bar{\alpha}=2 \operatorname{Re}(\alpha)$

$\mathrm{q}=\alpha \bar{\alpha}=\rho^{2}$;

$Q=x^{2}+p x+q$

$T(x)=\sum_{i=0}^{n}\left|a_{i}\right| x^{n-i}$

$\alpha_{k}$ is an approximate root of $P(x)=0$;

$\delta=$ the pivotal bound;

$\epsilon=$ the tolerated relative error of $\alpha_{\mathrm{k}}$ with respect to $\left(\rho_{\mathrm{k}}\right)_{\mathrm{t}}$;

$\eta=$ the separation coefficient;

$\nu=$ the multiplicity of roots of modulus $(\mu)_{t}$ of $F(x)$;

$\rho=|\alpha|$

$t$ as a subscript indicates the true value of a number instead of its approximation;

$\mathrm{n}$ as a subscript indicates the degree of a polynomial. 


\section{DESCRIPTION OF THE METHOD}

The solution is obtained in four major steps.

Step 1

We first determine the moduli $\rho_{k}$ and their multiplicity $\nu_{k}$ of the zeros of the given polynomial $P_{n}(x)$ of degree $n$ in the same way as in the Resultant Procedure described in Reference 1.

Step 2

Starting with the smallest $\rho_{k}$, we test whether $\alpha_{k}= \pm \rho_{k}$ is a real root of $P_{n}(x)$. If it is, we divide the factor $x-\alpha_{k}$ into $P_{n}(x)$ and thereby reduce the degree of $P_{n}(x)$ by one:

$$
P_{n}(x)=\left(x-\alpha_{k}\right) P_{n-1}(x)
$$

If the multiplicity of $\rho_{\mathrm{k}}$ is larger than 1 , we test whether $\alpha_{\mathrm{k}}= \pm \rho_{\mathrm{k}}$ is a real root of $P_{n-1}(x)$, etc. This is continued until the multiplicity of $\rho_{k}$ is satisfied, or until $\pm \rho_{k}$ fails the test and hence is the modulus of a complex root. Then we take the next smallest $\rho_{k}$ and so on, and repeat this process for each $\rho_{k}$ until no real zeros are left. Therefore we are left with a polynomial $\mathrm{P}_{\ell}(\mathrm{x})(\ell \leq \mathrm{n})$ with only complex zeros.

Remark: Dividing the linear factors out is a departure from the conservative approach used in Reference 1 where each linear factor was tested on the given polynomial $P(x)$. The reason for doing this is to make the final code faster. To minimize the effects of the round-off errors (see References 8 and 9) in the factorization process, we started with the smallest $\rho_{\mathrm{k}}$. Also, all arithmetic operations are done in double precision.

$\underline{\text { Step } 3}$

To determine the quadratic factors (i.e., the pairs of complex zeros), we construct the reduced subresultant for $P_{\ell}(x)$ and $Q(x)=x^{2}+p x+\rho_{k}^{2}$, where $\rho_{k}$ is the smallest modulus whose multiplicity $\nu_{k}$ after Step 2 indicates the existence of such a quadratic factor. This reduced subresultant is a polynomial of order $l-3$ in $p$. Since $p$ must be real, we obtain its absolute value by the root-squaring routine used in Step l. We test whether $\mathrm{x}^{2} \pm|\mathrm{p}| \mathrm{x}+\rho_{\mathrm{k}}^{2}$ is a factor of $\mathrm{P}_{\ell}(\mathrm{x})$. If it is, we divide this factor into $\mathrm{P} \ell(\mathrm{x})$ and reduce the polynomial to one of degree $l-2$. If the multiplicity of. $\rho_{k}$ is not satisfied, we repeat Step 3 with $\rho_{k}$ and $P_{\ell_{-2}}(x)$. Then we proceed to the next smallest $\rho_{\mathrm{k}}$ that indicates the existence of a quadratic factor, and so on. 
Remark: The reasons for this flow of operations are the same as those given for Step 2. In addition, we do not check immediately for quadratic factors of higher multiplicity since, in our experience, they do not occur frequently enough in practical problems but are still obtained in the following repetitions of Step 3. Thus, the most unlikely polynomials will take more time for their complete factorization than the more common ones. Should we, for some reason, be left with a nonconstant remainder, say a polynomial of degree $S$, the code solves the remaining polynomial equation $P_{S}(x)=0$ as a new problem and adds the roots to the set of already-determined zeros of $P_{n}(x)$.

If there should still be some roots missing, an adjustment to the standard setting is made automatically by the computer.

Step 4

After the given polynomial $\mathrm{P}_{\mathrm{n}}(\mathrm{x})$ is completely factorized, all factors are multiplied together in double precision to generate a polynomial of order $n$, whose coefficients are adjusted by the factor $a_{0}$ of $P_{n}(x)$. By comparing. the input coefficients $a_{i}$ and the generated coefficients of the polynomials, one can estimate whether the factorization represents a satisfactory approximation to the true solution of $P_{n}(x)$. References 3,4 , 8,9 contain detailed information concerning this.

Remark: Most polynomials encountered at Argonne contain approximate coefficients $a_{j}$. The users seem to be pleased to have a check for the solution in the form described in Step 4. 


\section{DESCRIPTION OF THE RSSR CODE}

In this section, we list the actual mathematical formulas as they are used in the RSSR code. The logical flow of operations is indicated by the flow charts (Figs. 1 to 4 ).

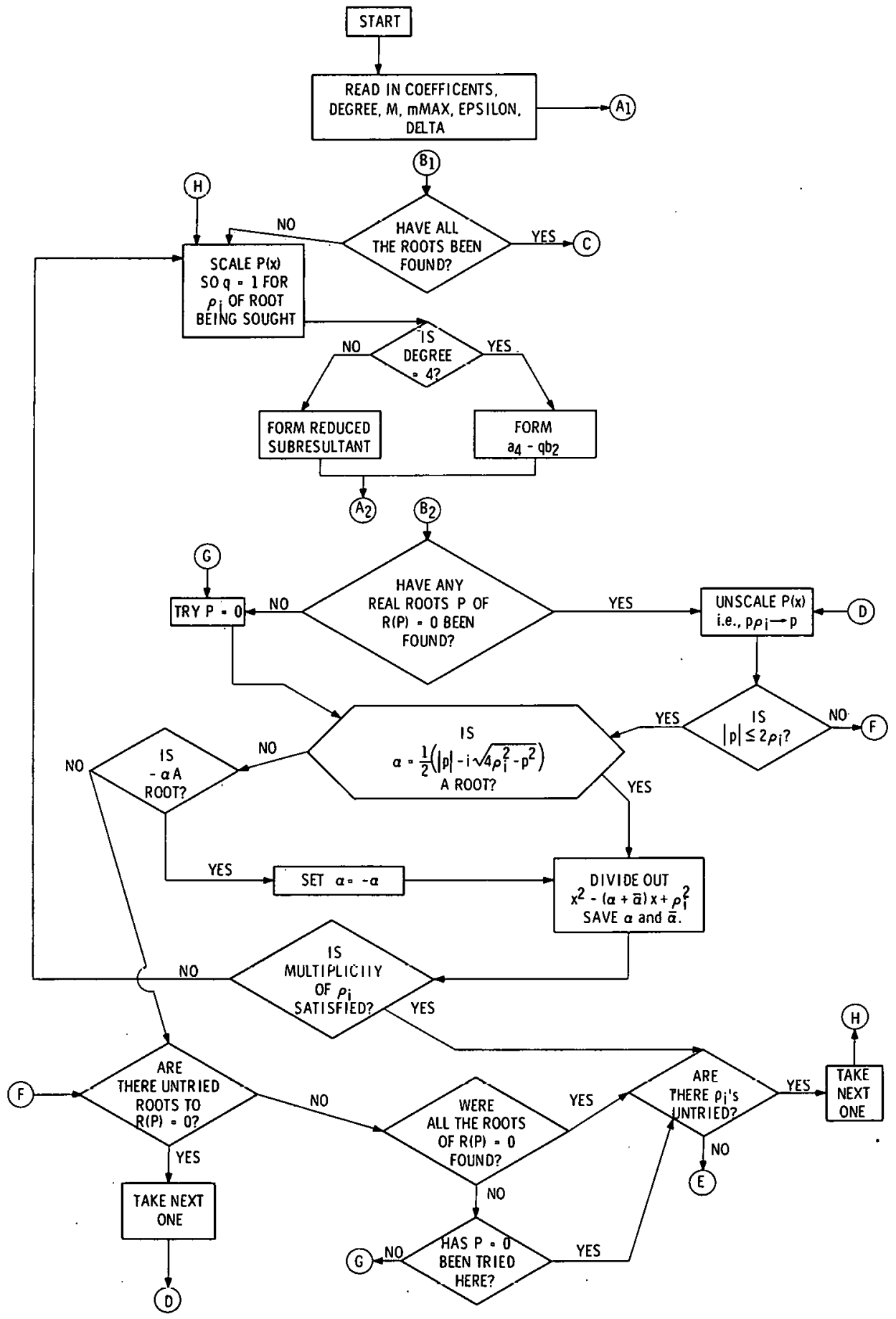

Fig. 1.. RSSR Subroutine 


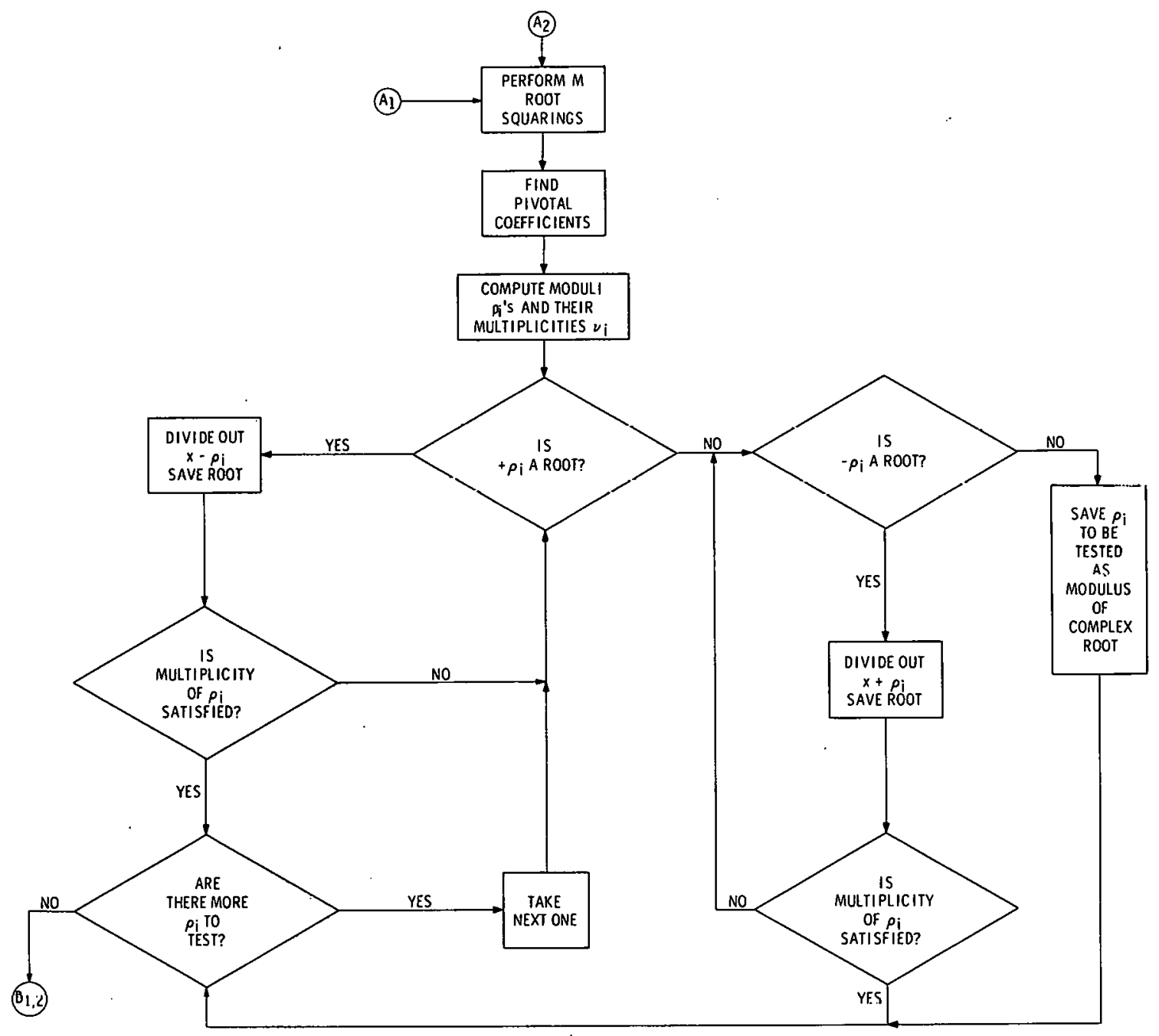

Fig. 2. Finding of Moduli of Roots and Real Roots

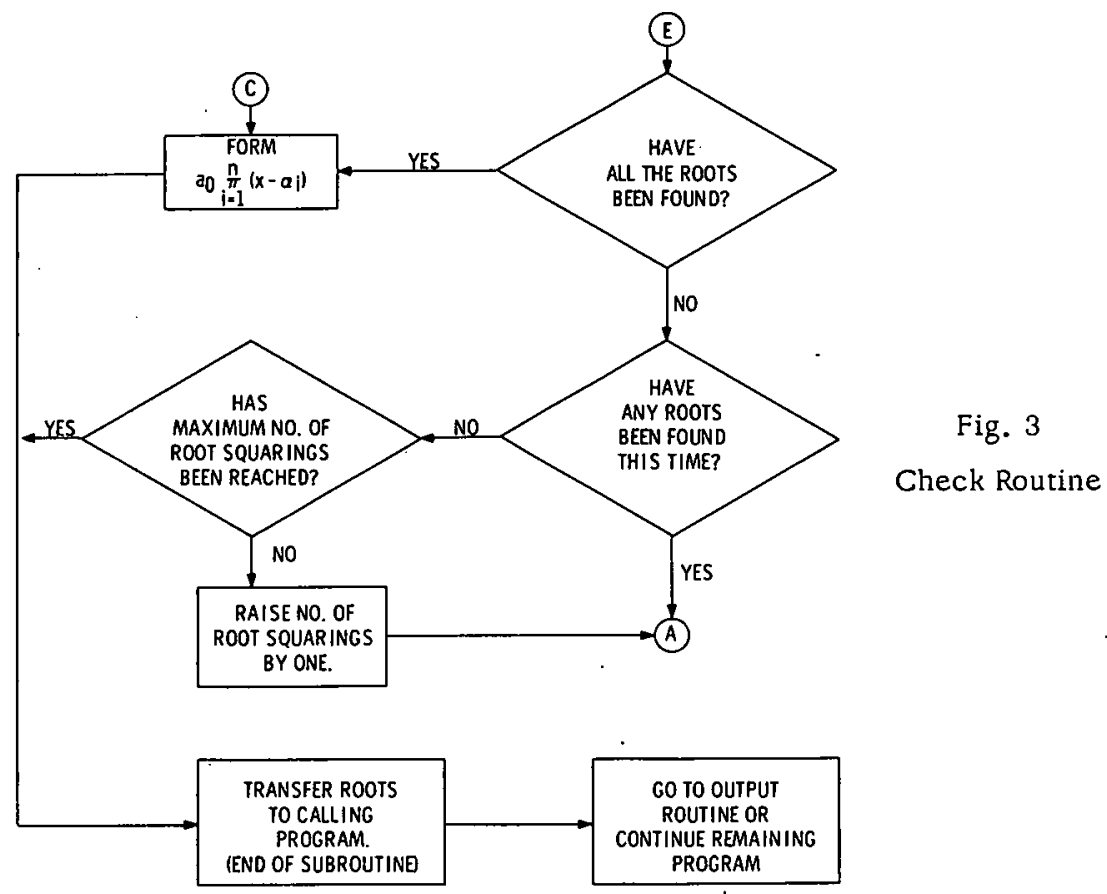




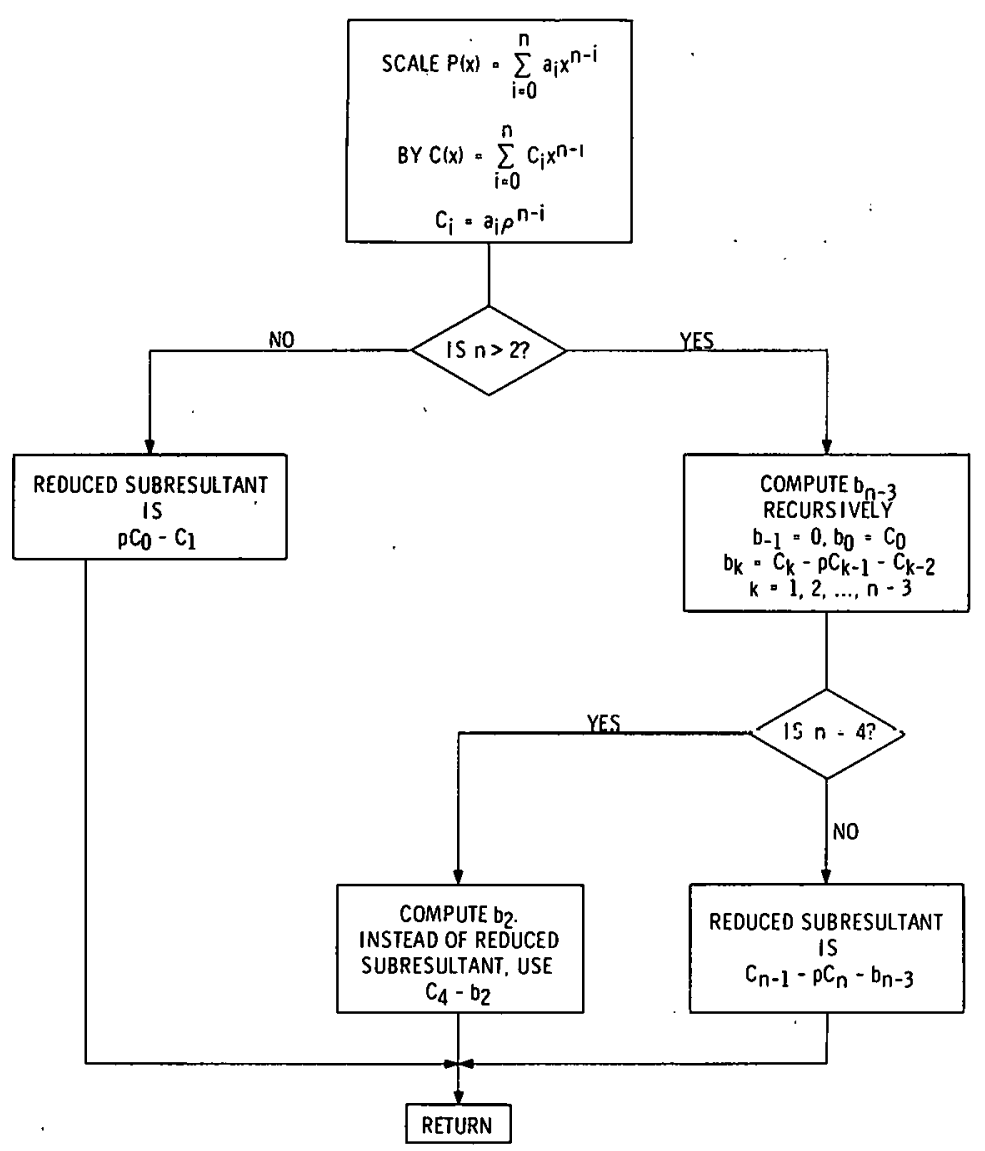

Fig. 4. Flow Chart for Finding the Reduced Subresultant Polynomial

Step 1

\section{Preliminary Considerations}

$M, \delta$, and $\epsilon$ have to be chosen. Reference l contains theoretical discussions and tables on these quantities. The standard setting in RSSR is $M=10, \delta=10^{-4}$, and $\epsilon=10^{-6}$. When $\mathrm{n}$ is large and the roots are close together, i.e., $\alpha_{j} / \alpha_{j+1}$ is near one, an $\epsilon$ considerably smaller may be needed with $\mathrm{M}=20$ or more. Examples are included in Appendix A.

Determination of the Moduli $\rho$ of the Roots $\alpha$

(1) The squaring operations are

$$
a_{j}^{(m+1)}=(-1)^{j}\left\{\left(a_{j}^{(m)}\right)^{2}+2 \sum_{l=1}^{\min (n-j, j)}(-1)^{\ell} a_{j-l}^{(m)} a_{j+l}(m)\right\}
$$

where $a_{j}^{(0)}=a_{j} ; j=0,1, \ldots, n ; m=0,1, \ldots, M-1$. The terms $\left(a_{j}(m)\right)^{2}$ are
added last to reduce the rounding errors (see Reference 1$).$ 
(2) Next, the pivotal coefficients are found. A coefficient $a_{j}^{(m)}$ is pivotal if

$$
\left|1-(-1)^{j} \frac{\left[a j^{(m-1)}\right]^{2}}{a_{j}^{(m)}}\right|<\delta .
$$

Notice that $a_{0}^{(m)}$ and $a_{n}^{(m)}$ are always pivotal and need not be tested.

(3) The multiplicity $\nu$ of the moduli $\rho$ is determined from successive pivotal coefficients. The moduli $\rho$ of the roots $\alpha$ are

$$
\rho=\left[\frac{(-1)^{\nu} a_{k+\nu}^{(M)}}{a_{k}^{(M)}}\right]^{\frac{1}{2^{M_{\nu}}}}
$$

$\underline{\text { Step } 2}$

$\alpha= \pm \rho$ is tested as a root. The acceptance test is shown under Step $3 b$ below.

Step 3.

a. Determination of the Complex Roots $\alpha$ of Modulus $\rho$

(1) The subresultant $R_{1}(p)$ is computed as follows: Assume $Q=x^{2}+p x+q$ to be a factor of $P_{n}(x)$. . Then

$$
P_{n}(x)=\left(x^{2}+p x+q\right) P_{n-2}(x)
$$

and

$$
P_{n-2}(x)=\cdot \sum_{i=0}^{n-2} b_{i} x^{n-2-i}
$$

where

$$
\begin{aligned}
& b_{-1}=0 \\
& b_{0}=a_{0}
\end{aligned}
$$

and

$$
b_{k}=a_{k}-p b_{k-1}-g b_{k-2}, \quad k=1,2, \ldots, n-2 .
$$


(2) The remainder in the division of $P(x)$ by $x^{2}+p x+q$ is zero;

i.e.,

$$
R=a_{n}-b_{n-2} q=0,
$$

and

$$
R_{1}=a_{n-1}-b_{n-3} q-b_{n-2} P=0 \text { (subresultant). }
$$

Hence,

$$
b_{n-2}=a_{n} / q
$$

Substituting this in the expression for $R_{1}$ yields

$$
R_{1}=a_{n-1}-b_{n-3} q-\frac{a_{n}}{q} p=0
$$

Since we know $q=\rho^{2}$ in the quadratic factor, the last equation is a polynomial equation in $p$,

$$
R_{1}(p)=0 \text {. }
$$

We call this polynomial, $R_{1}(p)$, the reduced subresultant. Since $b_{k}$ is a polynomial of degree $k$ in $p, R_{1}(p)$ is of degree $n-3$ for $n \geq 4$; otherwise it is linear in $p$ because of the term $\left(a_{n} / q\right) p$. When $n=4$, the reduced subresultant is

$$
a_{3}-b_{1} q-\left(a_{4} / q\right) p=0 .
$$

Since $p$ enters linearly in $b_{1}$ as well as in $\left(a_{4} / q\right) p$, the coefficient of $p$ can vanish. To avoid this, we use

$$
a_{4}-b_{2} q=0
$$

instead of the reduced subresultant whenever the degree of $P(x)$ is $n=4$.

(3) We solve $\mathrm{R}(\mathrm{p})=0$ for real roots $\mathrm{p}$ by the method of Step 1. The roots $p$ such that $|p| i<2 p$ then lead to complex roots of $P_{n}(x)$ as follows:

$$
\begin{aligned}
& \text { If } Q=x^{2} \pm|p| x+\rho^{2} \text { is a quadratic factor of } P_{n}(x) \text {, then } \\
& \alpha=\mp \frac{1}{2}\left(|p| \pm i \sqrt{4 \rho^{2}-p^{2}}\right) .
\end{aligned}
$$

The acceptance test is shown in paragraph $\mathrm{b}$ below. 
Remark: In the actual code, the coefficients of $P_{n}(x)$ are modified so that

$$
P_{n} \Longrightarrow \sum_{i=0}^{n} \check{a}_{i} x^{n-1}
$$

where

$$
\tilde{a}_{i}=a_{i} \rho^{n-i}(i=0,1, \ldots, n)
$$

Then the corresponding root $\tilde{\alpha}$ has a modulus of unit length, $|\tilde{\alpha}|=\tilde{\rho}=1$, and

$$
Q=x^{2}+\tilde{p} x+1
$$

Thus the calculation of the coefficients for $R_{1}(p)$ can be reduced to shift operations and additions only, since $q=1$.

b. Testing of Roots

(1) We compute for $k=1,2, \ldots, n, n+1$,

$b_{k}=a_{k}-w b_{k-1}-q b_{k-2}\left(b-1=0, b_{0}=a_{0}, a_{n+1}=0\right)$.

To test if $\left\{\begin{array}{l}x-\alpha \\ x^{2}+p x+\rho^{2}\end{array}\right\}$ is a factor of $P(x)$, set

$$
\left\{\begin{array}{l}
w=-\alpha, q=0 \\
w=p, q=\rho^{2}
\end{array}\right\} \text {. }
$$

(2) The approximation is considered sufficient when

$$
T(\rho+2 \epsilon \rho)-T(\rho+\epsilon \rho)>\left\{\begin{array}{ll}
\left|b_{n}\right| & \text { for } x-\alpha \\
\sqrt{b_{n}^{2}-b_{n-1} b_{n+1}} & \text { for } x^{2}+p x+\rho^{2}
\end{array}\right\} .
$$

\section{Step 4}

The regeneration of the coefficients of $P_{n}(x)$ is done by nesting as follows:

Let $\alpha_{1}, \alpha_{2}, \ldots, \alpha_{n}$ be the computed roots obtained for $P_{n}(x)=0$. They are arranged so that complex roots and their conjugates are in adjacent locations. Then, approximately,

$P_{n}(x)=\left\{\left\{\ldots\left[\left(x^{2}-2 x \operatorname{Re} \alpha_{n}+\left|\alpha_{n}\right|^{2}\right)\left(\dot{x}^{2}-2 \operatorname{xRe} \alpha_{n-2}+\left|\alpha_{n-2}\right|^{2}\right)\right] \ldots\left(x-\alpha_{2}\right)\right\}\left(x-\alpha_{1}\right)\right\} a_{0} \cdots$ 


\section{COMPARISON WITH OTHER METHODS}

The remarks in the introduction indicate that many of the well-known iterative methods, such as the Newton-Raphson, Bairstow-Hitchcock, Lin, and others, are also resultant procedures.

The special feature of the procedures discussed in Reference 1 and in this paper is that we intersect the surface of the algebraic functions

$$
R(p, q)=0
$$

and

$$
R_{1}(p, q)=0
$$

by a plane $q=\rho^{2}$ and thus are able to reduce the entire problem to finding real roots of real polynomial equations. One can see from geometrical consideration that such an approach yields a better overall numerical stability.

Unfortunately the title of Reference l led some readers to believe that the Resultant Procedure is a mechanization of the Graeffe process. We should like to demonstrate on a simple example that this is not so.

Take the accurate polynomial equation

$$
p(m)(x)=: x^{2}-2 a x+a^{2}=0
$$

Assume now that in the process of root squaring, a small error was introduced in the constant term, such that

$$
P^{(m)}(x)=x^{2}-2 a x+a^{2}(1-\epsilon) .
$$

Then, with the methods described in the literature, we have, by the Graeffe method,

$$
\alpha_{1,2}^{\left({ }^{m}\right)}=a(1 \pm \sqrt{\epsilon})
$$

while by the Resultant Procedure and RSSR Routine,

$$
\alpha_{1 ; 2}^{\left(2^{r \lambda}\right)}=a \sqrt{1-\epsilon} \approx \dot{a} \cdot\left(1-\frac{\epsilon}{2}\right)
$$

Assume now, that in the process of root squaring, a small error is introduced in the middle term such that

$$
\mathrm{P}(\mathrm{m})(\mathrm{x})=\mathrm{x}^{2}-2(1+\epsilon) a x+\mathrm{a}^{2}
$$


Then, with the methods described in the literature we have, by the Graeffe method,

$$
\alpha_{1,2}^{\left(2^{m}\right)}=a\left(1+\epsilon \pm \sqrt{2 \epsilon+\cdot \epsilon^{2}}\right)
$$

while by the Resultant Procedure and RSSR Routine,

$$
\alpha_{1,2}^{\left({ }^{m} \mathrm{~m}\right)}=\mathrm{a} .
$$

This exhibits quite clearly that the behavior with respect to numerical stability is quite different than in the Graeffe method and in favor of the resultant procedures of Reference 1 .

In addition, we have already given in Reference 1 examples that cannot be solved by the "Graeffe" method and by many of the well-known "standard" iterative methods, but can be solved by the resultant procedures. Such problems are generally polynomial equations which contain cyclotomic factors and/or multiple real and/or complex roots.

We believe that the resultant procedures belong to the better "allpurpose methods" for practical use in research centers when all zeros of a polynomial are desired. We plan to improve our codes as time goes on, taking advantage of other research results such as presented in References 3 , 4 , 7, etc., should our experience show such changes to be desirable for practical applications. 


\section{APPENDIX A}

\section{Numerical Examples}

\section{Some General Remarks}

We present here a number of test polynomials and some short remarks relating to their particular point of interest. While we endeavored to design a routine that accepts any polynomial of practical interest, it will always be possible to find polynomials that cannot be solved with any given code.

It is always desirable that all coefficients be of the same order of magnitude. This can often be achieved by a transformation of the roots such that

$$
x \rightarrow 10^{r} x^{\prime}
$$

or

$$
x \rightarrow 2^{s} x^{\prime}
$$

If one suspects clustering of roots in the neighborhood of $z_{0_{0}}=x_{0}+i y_{0}$, the transformation

$$
x \rightarrow x_{0}-\mathbf{x}
$$

will increase the separation coefficient and thus reduce $M$.

Sometimes the transformation

$$
x \rightarrow \frac{1}{x}
$$

leads to somewhat better numerical behavior.

Such transformations must be considered as an exception, and for the solution of the following problems these transformations were not used.

2. Polynomials Solved

Example 1. The difficulty in the following polynomial is the high multiplicity of the modulus 2 :

$$
\begin{aligned}
x^{12}- & x^{11}+6 x^{10}-4 x^{9}-29 x^{8}+45 x^{7}-82 x^{6}+64 x^{5}-384 x^{4}+256 x^{3} \\
& +1856 x^{2}-2880 x+1152=\left(x^{6}-2^{6}\right)(x+2)\left(x^{2}+3^{2}\right)(x-1)^{3}=0
\end{aligned}
$$


The roots found with $M=9, \delta=10^{-5}$, and $\epsilon=10^{-8}$ are as follows:

\begin{tabular}{|c|c|c|c|c|c|c|c|c|c|}
\hline \multicolumn{5}{|c|}{ Real Part } & \multicolumn{5}{|c|}{ Imaginary Part } \\
\hline 1.1993 & 9865 & 3312 & 0892 & $801 \times 10^{-17}$ & -3.0000 & 0000 & 0000 & 0000 & 031 \\
\hline 1.1993 & 9865 & 3312 & 0892 & $801 \times 10^{-17}$ & 3.0000 & 0000 & 0000 & 0000 & 031 \\
\hline 9.9999 & 9999 & 9999 & 9999 & $399 \times 10^{-1}$ & -1.7320 & 5080 & 7568 & 8773 & 020 \\
\hline 9.9999 & 9999 & 9999 & 9999 & $399 \times 10^{-1}$ & 1.7320 & 5080 & 7568 & 8773 & 020 \\
\hline-1.0000 & 0000 & 0000 & 0000 & 082 & -1.7320 & 5080 & 7568 & 8772 & 887 \\
\hline-1.0000 & 0000 & 0000 & 0000 & 082 & 1.7320 & 5080 & 7568 & 8772 & 887 \\
\hline-1.9999 & 9999 & 9999 & 9999 & 999 & 0.0 & & & & \\
\hline-1.9999 & 9999 & 9999 & 9999 & 999 & 0.0 & & . & & \\
\hline 2.0000 & 0000 & 0000 & 0000 & 044 & 0.0 & & & & \\
\hline 1.0000 & 0000 & 0000 & 0000 & 000 & 0.0 & & & & \\
\hline 1.0000 & 0000 & 0000 & 0000 & 000 & 0.0 & & & & \\
\hline $1: 0000$ & 0000 & 0000 & 0000 & 000 & 0.0 & & & & \\
\hline
\end{tabular}

When the polynomial was reconstructed from these roots, the new coefficients agreed with the original ones to at least 16 digits.

Example 2. The difficult part of this polynomial is that the separation coefficient for the two largest roots is 0.001 :

$$
x^{4}-2020 x^{3}+1,039,109 x^{2}-19,199,090 x+90,090,000=0 .
$$

The roots found with $M=16, \delta=10^{-6}$, and $\epsilon=10^{-8}$, truncated, but not rounded, to 20 significant figures, are:

\begin{tabular}{llllll} 
& \multicolumn{3}{c}{ Real Part } & Imaginary Part \\
\cline { 3 - 6 } 1.0009 & 9999 & 9999 & 9999 & $999 \times 10^{3}$ & 0.0 \\
1.0000 & 0000 & 0000 & 0000 & $0.00 \times 10^{3}$ & 0.0 \\
9.9999 & 9999 & 9999 & 9999 & 999 & 0.0 \\
8.9999 & 9999 & 9999 & 9999 & 999 & 0.0
\end{tabular}

When the coefficients were reconstructed from the se roots, the new coefficients agreed with the original one s to at least 19 significant digits. The true roots are $9,10,1000$, and 10.01 . 
Example 3. This is the transformed Chebyshev polynomial $\frac{1}{2} \mathrm{~T}_{20}(\mathrm{x} / 2)$. The difficulty here is that the smallest separation coefficient, $\eta$, is . $1-\alpha_{k+1} / \alpha_{k}=0.0246$ :

$$
\begin{aligned}
x^{20}- & 20 x^{18}+170 x^{16}-800 x^{14}+2275 x^{12}-4004 x^{10}+4290 x^{8}-2640 x^{6} \\
+ & 825 x^{4}-100 x^{2}+2=0
\end{aligned}
$$

The roots found (all real) with $M=10, \delta=10^{-6}$, and $\epsilon \Rightarrow 10^{-8}$ are as follows:

$$
\begin{array}{lllll}
-1.9938 & 3466 & 7466 & 2556 & 788 \\
+1.9938 & 3466 & 7466 & 2556 & 788 \\
-1.9447 & 3984 & 0795 & 3535 & 493 \\
+1.9447 & 3984 & 0795 & 3535 & 493 \\
-1.8477 & 5906 & 5022 & 5734 & 865 \\
+1.8477 & 5906 & 5022 & 5734 & 865 \\
-1.7052 & 8032 & 8708 & 1843 & 987 \\
+1.7052 & 8032 & 8708 & 1843 & 987 \\
-1.5208 & 1193 & 1200 & 0618 & 698 \\
+1.5208 & 1193 & 1200 & 0618 & 698 \\
-1.2988 & 9609 & 6660 & 3673 & 133 \\
+1.2988 & 9609 & 6660 & 3673 & 133 \\
-1.0449 & 9712 & 9431 & 8977 & 302 \\
+1.0449 & 9712 & 9431 & 8977 & 302 \\
+-7.6536 & 6864 & 7301 & 7954 & 346 \times 10^{-1} \\
+7.6536 & 6864 & 7301 & 7954 & 346 \times 10^{-1} \\
-4.6689 & 0727 & 7118 & 1082 & 353 \times 10^{-1} \\
+4.6689 & 0727 & 7118 & 1082 & 353 \times 10^{-1} \\
-1.5691 & 8191 & 4556 & 8989 & 006 \times 10^{-1} \\
+1.5691 & 8191 & 4556 & 8989 & 006 \times 10^{-1}
\end{array}
$$

The coefficients found from the roots agree to at least 17 significant digits with the original ones. 
Example 4. No particular difficulty is presented by this polynomial. It simply demonstrates that a quadratic can be handled by the resultant procedure without any trouble.

$$
\begin{aligned}
& x^{2}-2 x+2=0 . \\
& \text { Roots found, } M=4, \delta=10^{-4}, \epsilon=10^{-6}: \\
& 0.999999 \pm 0.9999999 i \\
& \text { Example } 5 \\
& x^{4}+x^{8}+x^{7}+x^{6}+x^{5}+x^{4}+x^{3}+x^{2} \equiv x^{2} \frac{x^{8}-1}{x-1}=0 .
\end{aligned}
$$

This polynomial demonstrates several aspects of the RSSR Routine.

a) It contains a cyclotomic factor whose zeros are the primitive $8^{\text {th }}$ roots. Such a polynomial cannot be solved with the usual Graeffe procedure. It represents no difficulty with the resultant procedures (see Reference 1).

b) It contains a high multiplicity in the modulus of the roots with absolute value 1 .

c) It contains pure imaginary zeros.

d) It contains a double zero as a factor.

The accurate values for the zeros are

$$
(1 \pm i) \sqrt{1 / 2}, \pm i,(-1 \pm i) \sqrt{1 / 2},-1,0,0 .
$$

The results found by the CDC-3600 with $M=5, \delta=0.005$, and $\epsilon=10^{-6}$ are as follows:

\begin{tabular}{rllllllllll} 
& & \multicolumn{3}{c}{ Real Part } & \multicolumn{5}{c}{ Imaginary Part } \\
\cline { 3 - 11 } 7.07106 & 78118 & 65475 & 24400 & $84453 \times 10^{-1}$ & -7.07106 & 78118 & 65475 & 24400 & $84416 \times 10^{-1}$ \\
7.07106 & 78118 & 65475 & 24400 & $84453 \times 10^{-1}$ & 7.07106 & 78118 & 65475 & 24400 & $84416 \times 10^{-1}$ \\
-7.31131 & 27550 & 28601 & 08107 & $97448 \times 10^{-26}$ & -1.00000 & 00000 & 00000 & 00000 & 00000 \\
-7.31131 & 27550 & 28601 & 08107 & $97448 \times 10^{-26}$ & 1.00000 & 00000 & 00000 & 00000 & 00000 \\
-7.07106 & 78118 & 65475 & 24400 & $84437 \times 10^{-1}$ & -7.07106 & 78118 & 65475 & 24400 & $84428 \times 10^{-1}$ \\
-7.07106 & 78118 & 65475 & 24400 & $84437 \times 10^{-1}$ & 7.07106 & 78118 & 65475 & 24400 & $84428 \times 10^{-1}$ \\
-1.00000 & 00000 & 00000 & 00000 & 00000 & 0.00000 & 00000 & 00000 & 00000 & 00000 \\
0.00000 & 00000 & 00000 & 00000 & 00000 & 0.00000 & 00000 & 00000 & 00000 & 00000 \\
0.00000 & 00000 & 00000 & 00000 & 00000 & 0.00000 & 00000 & 00000 & 00000 & 00000
\end{tabular}


These roots are accurate to at least 23 decimal places (the limitations of the $\log \mathrm{x}, \mathrm{e}^{\mathrm{x}}$ subroutines). Total calculation time on CDC-3600 is less than 2 sec.

The check routine yields the following results:

Input Coefficients

Reconstructed Polynomial

$a_{0}=1.00000 \cdot 00000 \quad a_{0}=\begin{array}{lllllll}1.00000 & 00000 & 00000 & 00000 & 00000 & 0\end{array}$

$a_{1}=1.00000 \quad 00000 \quad a_{1}=\begin{array}{lllllll}1.00000 & 00000 & 00000 & 00000 & 00000 & 0\end{array}$

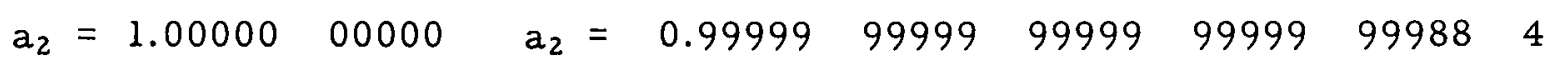

$a_{3}=1.00000 \quad 00000 \quad a_{3}=0.99999 \quad 99999 \quad 99999 \quad 99999 \quad 999834$

$\mathrm{a}_{4}=1.00000 \quad 00000 \quad \mathrm{a}_{4}=\begin{array}{lllllll}0.99999 & 99999 & 99999 & 99999 & 99.983 & 4\end{array}$

$a_{5}=1.00000 \quad 00000: a_{5}=0.99999999999999999999 \quad 99986 \quad 7$

$a_{6}=1.00000 \quad 00000 \quad a_{6}=\begin{array}{llllll}0.99999 & 99999 & 99999 & 99999 & 99996 & 6\end{array}$

$a_{7}=1.00000 \quad 00000 \quad a_{7}=1.00000 \quad 00000 \quad 00000 \quad 00000 \quad 00000 \quad 0$

$a_{8}=0.00000 \quad 00000 \quad a_{8}=-0.00000 \quad 00000 \quad 00000 \quad 00000 \quad 00000 \quad 0$

$a_{9}=0.00000 \quad 00000 \quad a_{9}=\begin{array}{lllllll}0.00000 & 00000 & 00000 & 00000 & 00000 & 0\end{array}$

The following three polynomial equations (Examples 6, 7, and 8) are given in Wilkinson ${ }^{8,9}$ and known to be extremely difficult to solve.

Example 6. This is a polynomial which Oliver and Wilkinson ${ }^{8}$ consider too difficult for the Graeffe process. It can be solved by the RSSR Routine.

$$
\begin{aligned}
& 2.03253121 x^{16}+3.4356048 x^{15}+25.1783048 x^{14}+37.651096 x^{13} \\
& \quad 128.218748 x^{12}+166.44768 x^{11}+345.07256 x^{10}+378.908 x^{9} \\
& +524.327 x^{8}+468.88 x^{7}+443.576 x^{6}+304.08 x^{5}+190.68 x^{4}+89.6 x^{3} \\
& +32.8 x^{2}+8 x+1=0 .
\end{aligned}
$$

The solution was found with $M=30, \delta=10^{-6}$, and $\epsilon=10^{-7}$. We give a complete reproduction of the CDC -3600 output." The roots found are as follows: 
REAL PART

$-2.4892024459300534091983319-003$

$-2.4892024459300534091983319-003$

$-1.0493550094786246139124231-002$

$-1.0493550094786246139124231-002$

$-2.5668710501835624507950315-002$

$-2.5668710501835624507950315-002$

$-5.0864435604355134377307702-002$

$-5.0864435604355134377307702-002$

$-9.0039988741533156123763808-002$

$-9.0039988741533156123763808-002$

$-1.4762378022667001866562007-001$

$-1.4762378022667001866562007-001$

$-2.2447005787902159556593484-001$

$-2.2447005787902159556593484-001$

$-2.9350452923438473849175751-001$

$-2.9350452923438473849175751-001$
IMAGINARY PART

$-1.6671203612177835792153141+000$

$1.6671203612177835792153141+000$

$-1.5962954955540975249059991+000$

$1.5962954955540975249059991+000$

$-1.4743771438266904040684607+000$

$1.4743771438266904040684607+000$

$-1.2969112790733189623891615+000$

$1.2969112790733189623891615+000$

$-1.0611920598431853135487569+000$

$1.0611920598431853135487569+000$

$-7.7175720106385244613338246-001$

$7.7175720106385244613338246-001$

$-4.5092795830149006994849992-001$

$4.5092795830149006994849992-001$

$-1.4349929692750051258853104-001$

$1.4349929692750051258853104-001$ 


\section{INPUT CCEFFICIENTS}
$A(0)=2.0325312099999999999999999+000$
A( 1$)=3.4356047999999999999999998+000$
A( 2$)=2.5178304800000000000000000+001$
Al 3$)=3.7651096000000000000000002+001$
A( 4$)=1.2821874800000000000000001+002$
$A(5)=1.6644767999999999999999999+002$
A( 6$)=3.4507255999999999999999999+002$
A( 7$)=3.7890799999999999999999998+002$
Al $81=5.2432700000000000000000000+002$
$A(.9)=4.6887999999999999999999999+002$
$A(10)=4.4357600000000000000000005+002$
$A(11)=3.0408000000000000000000004+002$
$A(12)=1.9067999999999999999999999+002$
$A(13)=8.9600000000000000000000016+001$
$A(14)=\quad 3.2799999999999999999999999+001$
$A(15)=8.0000000000000000000000000+000$
$A(16)=1.0000000000000000000000000+000$
Al $01=2.0325312099999999999999999+000$
Al $I 1=3.4356047999999999999999994+000$
Al $21=2.5178304799999999999690499+001$
Al $31=3.7651096000000000037341495+001$
A1. $41=1.2821874800000000006004599+002$
Al 51$)=1.6644768000000000026143183+002$
A( 6$)=3.4507256000000000034586439+002$
A( 7$)=3.7890800000000000067958806+002$
$A(8)=5.2432700000000000070546032+002$
$A(9)=4.6888000000000000080750189+002$
$A(10)=4.4357600000000000061799823+002$
$A(11)=3.0408000000000000043061875+002$
$A(12)=1.9068000000000000021698943+002$
$A(13)=8.9600000000000000083556061+001$
$A(14)=3.2800000000000000020944971+001$
$A(15)=8.0000000000000000026291505+000$
$A(16)=1.0000000000000000000000002+000$

\section{RECONSTRUCTED POLYNOMIAL}


From the reconstructed coefficients, we can estimate an accuracy of 18 significant figures in the zeros.

Example 7. The difficulty in the following example is that all roots are complex with absolute values close together. Five pairs of roots are clustered around the imaginary axis.

$$
\begin{aligned}
& 1250162561 x^{16}+385455882 x^{15}+845947696 x^{14}+240775148 x^{13} \\
& +247926664 x^{12}+64249356 x^{11}+41018752 x^{10}+9490840 x^{9} \\
& +4178260 x^{8}+83.7860 x^{7}+267232 x^{6}+44184 x^{5}+10416 x^{4} \\
& +1288 x^{3}+224 x^{2}+16 x+2=0 .
\end{aligned}
$$

\begin{tabular}{|c|c|c|c|c|c|c|}
\hline 0.13244 & 72469 & 90246 & $20179 \pm 0.13600$ & 55079 & 51377 & 63785 \\
\hline-0.01869 & 49953 & 44576 & $20320 \pm 0.25304$ & 56818 & 77088 & 48212 \\
\hline-0.00232 & $1 \ldots \ldots$ & & $\cdots \pm 0.29258$ & 374 & & \\
\hline-0.00049 & 1 & & $\cdots \pm 0.30418$ & $2 \ldots$ & & \\
\hline-0.00000 & & &. \pm 0.30857 & & & \\
\hline-0.0006 & $\ldots$. & & $\ldots \ldots \pm 0.3105$ & $\cdot$ & & \\
\hline-0.0003 & & . & $\ldots \ldots \pm 0.3125$ & 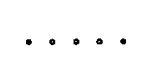 & & \\
\hline 0.0007 & & & 0.3116. & & & \\
\hline
\end{tabular}

The roots found with $M=24, \delta=10^{-8}$, and $\epsilon=10^{-11}$ on the CDC-3600 are as follows:

Figures which are believed doubtful (by comparison with the results given in Reference 8 ) are replaced by dots. The reconstruction of the original polynomial from the calculated roots gave an agreement in the coefficients. from 25 significant figures for $a_{1}$ down to 10 significant figures for $a_{16}$. We attribute the gradual loss of accuracy in the roots, to the deflation process and the use of the reduced subresultant. This is the price we may some-: times pay for high speed. If greater accuracy should be needed than to at least four decimal places, as given above, one makes the transformation $x=z-0.3 i$ and solves the complex polynomial $P_{16}(z-0.3 i)=0$ (see Reference 1). (Of course, higher-precision arithmetic could be applied too.)

Example 8. This polynomial was constructed by Wilkinson ${ }^{8}$ to demonstrate the possible sensitivity of roots to small changes in the coefficients. It is presented here to demonstrate that the RSSR Routine can handle such problems.

$$
P_{20}(x)=(x+1)(x+2)(x+3) \ldots(x+19)(x+20)+2^{-23} x^{19}
$$


The coefficients as computed by the CDC-3600 are listed below in the left column. The coefficients of the polynomial as reconstructed by the roots found with the RSSR Routine are listed in the right column for comparison. The agreement is to at least 18 significant decimal figures.

Input Coefficients

$a_{0}=1.0000000000000000000000000$

$a_{1}=2.1000000011920928955078126 \times 10^{2}$

$a_{2}=2.0614999999999999999999999 \times 10^{4}$

$a_{3} \cdot 1.2568500000000000000000001 \times 10^{6}$

$\mathrm{a}_{4}=5.3327945999999999999999992 \times 10^{7}$

$a_{5}=1.6722808199999999999999997 \times 10^{9}$

a6 $=4.01717 \quad 71630000000000000008 \times 10^{10}$

a7 $=7.56111 \quad 18449999999999999997 \times 10^{11}$

a8 $=1.1310276995380999999999999 \times 10^{13}$

$a_{9}=1.35585 \quad 18289 \quad 95299 \quad 99999 \quad 99999 \times 10^{14}$

$a_{10}=1.3075350105403950000000000 \times 10^{15}$

$a_{11}=1.0142299865511450000000000 \times 1016$

$\partial_{12} \cdot 0.30308 \quad 1209924489 \quad 60000000005 \times 10^{16}$

a13 $3.11333 \quad 64316 \quad 13996 \quad 39999 \quad 99995 \times 1017$

$a_{14}=1.20664 \quad 78037 \quad 80373 \quad 35999 \quad 99999 \times 10^{18}$

$\mathrm{a}_{15}=3.59997 \quad 9517947607 \quad 1999999996 \times 10^{18}$

$a_{16}=8.03781 \quad 18226 \quad 45051 \quad 77599 \quad 99983 \times 10^{18}$

$a_{17}=1.28709 \quad 31245 \quad 15098 \quad 88000 \quad 00001 \times 10^{19}$

$\partial_{18}=1.3803759753 \quad 640703999999999 \times 10^{19}$

$a_{19} \cdot 8.75294 \quad 80367 \quad 61599 \quad 99999 \quad 99994 \times 10^{18}$

a20 $=2.4329020081766399999999995 \times 10^{18}$
Reconstructed Polynomial

$a_{0}=1.0000000000000000000000000$

$a_{1}=2.1000000011920928955078126 \times 10^{2}$

$a_{2}=2.06149999999999999999 \quad 99999 \times 10^{4}$

$a_{3}=1.2568500000000000000000001 \times 10^{6}$

$\partial_{4}=5.3327945999 \quad 999999999999992 \times 10^{7}$

$a_{5}=1.6722808199 \quad 999999999991167 \times 10^{9}$

a $6=4.01717 \quad 7162999999 \quad 99998 \quad 85832 \times 10^{10}$

a7 $=7.56111 \quad 184499999999993 \quad 32566 \times 10^{11}$

$a_{8}=1.13102 \quad 76995 \quad 38099 \quad 99997 \quad 65947 \times 10^{13}$

ag $\cdot 1.35585 \quad 182899529999994 \quad 49547 \times 10^{14}$

${ }^{a_{10}}=1.30753 \quad 50105 \quad 40394 \quad 9999080801 \times 10^{15}$

$a_{11} \cdot 1.01422 \quad 99865 \quad 5114499988 \quad 75071 \times 10^{16}$

$a_{12}=6.30308 \quad 12099294895989740351 \times 10^{16}$

$a_{13}=3.11333 \quad 69316 \quad 13906 \quad 39929 \quad 83371 \times 10^{17}$

$a_{14}=1.20664 \quad 78037 \quad 80373 \quad 35964 \quad 11243 \times 10^{18}$

${ }_{1}{ }_{15}=3.59997 \quad 95179 \quad 47607 \quad 19864 \quad 33094 \times 10^{18}$

$a_{16}=8.03781 \quad 18226 \quad 45051 \quad 7722943019 \times 10^{18}$

${ }_{1}^{a} 17=1.28709 \quad 31245 \quad 15098 \quad 87929 \quad 63165 \times 10^{19}$

$a_{18}=1.38037 \quad 59753 \quad 64070 \quad 39912 \quad 99795 \times 10^{19}$

$\mathrm{a}_{19}=8.75294 \quad 80367 \quad 61599 \quad 9938060957 \times 1018$

$\mathrm{a}_{20} \cdot 2.43290 \quad 20081 \quad 7663999811 \quad 64034 \times 10^{18}$

The roots were found with $\mathrm{M}=12, \delta=1.5 \times 10^{-4}$, and $\epsilon=10^{-11}$ as follows:

\begin{tabular}{lllll} 
& & \multicolumn{2}{l}{ Real Part } \\
\cline { 4 - 5 }-1.39923 & 58137 & 23567 & 28477 & $71031 \times 10^{1}$ \\
-1.39923 & 58137 & 23567 & 28477 & $71031 \times 10^{1}$ \\
-1.17936 & 33881 & 07941 & 69417 & $55319 \times 10^{1}$ \\
-1.17936 & 33881 & 07941 & 69417 & $55319 \times 10^{1}$ \\
-1.95024 & 39400 & 49368 & 25733 & $05975 \times 10^{1}$ \\
-1.95024 & 39400 & 49368 & 25733 & $05975 \times 10^{1}$ \\
-1.67307 & 37466 & 09070 & 62233 & $93250 \times 10^{1}$ \\
-1.67307 & 37466 & 09070 & 62233 & $93250 \times 10^{1}$ \\
-1.00952 & 66145 & 12995 & 74203 & $55494 \times 10^{1}$ \\
-1.00952 & 66145 & 12995 & 74203 & $55494 \times 10^{1}$ \\
-2.08469 & 08101 & 48225 & 74613 & $16694 \times 10^{1}$ \\
-8.91725 & 02485 & 17118 & 77991 & 69465 \\
-8.00726 & 76034 & 50363 & 83908 & 58431 \\
-6.99969 & 72339 & 36015 & 54449 & 91110 \\
-6.00000 & 69439 & 52795 & 55757 & 68494 \\
-4.99999 & 99275 & 51537 & 92450 & 23621 \\
-4.00000 & 00002 & 61023 & 18783 & 43012 \\
-2.99999 & 999999 & 99805 & 23302 & 53595 \\
-2.00000 & 00000 & 00000 & 00976 & 16303 \\
-9.99999 & 99999 & 99999 & 99999 & $99693 \times 10^{-1}$
\end{tabular}

Imaginary Part

$\begin{array}{lllll}-2.51883 & 006 \% & 30280 & 51923 & 36702\end{array}$

$\begin{array}{lllll}2.51883 & 006 \% & 30280 & 51923 & 36702\end{array}$

$\begin{array}{lllll}-1.65232 & 97281 & 60931 & 55985 & 89243\end{array}$

$\begin{array}{lllll}1.65232 & 97281 & 60931 & 55985 & 89243\end{array}$

$\begin{array}{lllll}-1.94033 & 03466 & 64480 & 50888 & 58385\end{array}$

$\begin{array}{lllll}1.94033 & 03466 & 64480 & 50888 & 58385\end{array}$

$\begin{array}{lllll}-2.81262 & 48942 & 70039 & 28684 & 73528\end{array}$

$\begin{array}{lllll}2.81262 & 48942 & 70039 & 28684 & 73528\end{array}$

$-6.4350090386354431561619311 \times 10^{-1}$

$6.4350090386354431561619311 \times 10^{-1}$

The roots are believed accurate to at least 17 significant figures.

To conclude, we like to emphasize that some of the se examples are presented merely to demonstrate the inherent power of the code. Most requests for the solution of polynomials specify accuracy less than six significant digits. 
APPENDIX B

FORTRAN Statements

1. FORTRAN II Statements of the RSSR Routine as Coded for the IBM-704 Computer

a. Main Program

(Input and output procedures and call of subroutine RSSR)

b. Subroutine RSSR

(Master subroutine: Checks for zero roots. Calls root-squaring subroutine, RTSQ. Calls subroutine for finding moduli of roots and finding real roots, RERO. If complex roots exist, it calls subroutine COMPRT to find them. Calls subroutine RECON to reconstruct the polynomial.)

c. Subroutine RTSQ

(Root-squaring process)

d. Subroutine RERO

(Finds moduli and real roots, calls for test subroutine, TEST)

e. Subroutine TEST

(Tests roots for accuracy)

f. Subroutine COMPRT

(Finds complex roots and calls TEST)

g. Subroutine SUBRES

(Constructs the reduced subresultant polynomial)

h. Subroutine RECON

(Reconstructs the original polynomial from the computed zeros)

i. Subroutine QUADIV

(Divides out quadratic factors)

j. Subroutine DPOUTP

(Outputs double-precision numbers)

k. Subroutine SPCON

(Converts single-precision floating-point numbers to double precision) 


\section{Subroutine DPEX}

(Computes $\mathrm{e}^{\mathrm{x}}$ in double precision for double-precision $\mathrm{x}$ )

m. Subroutine DPLOG

(Computes double-precision natural logs for double-precision arguments) 
a. Main Program

(Input and output procedures and call of subroutine RSSR)

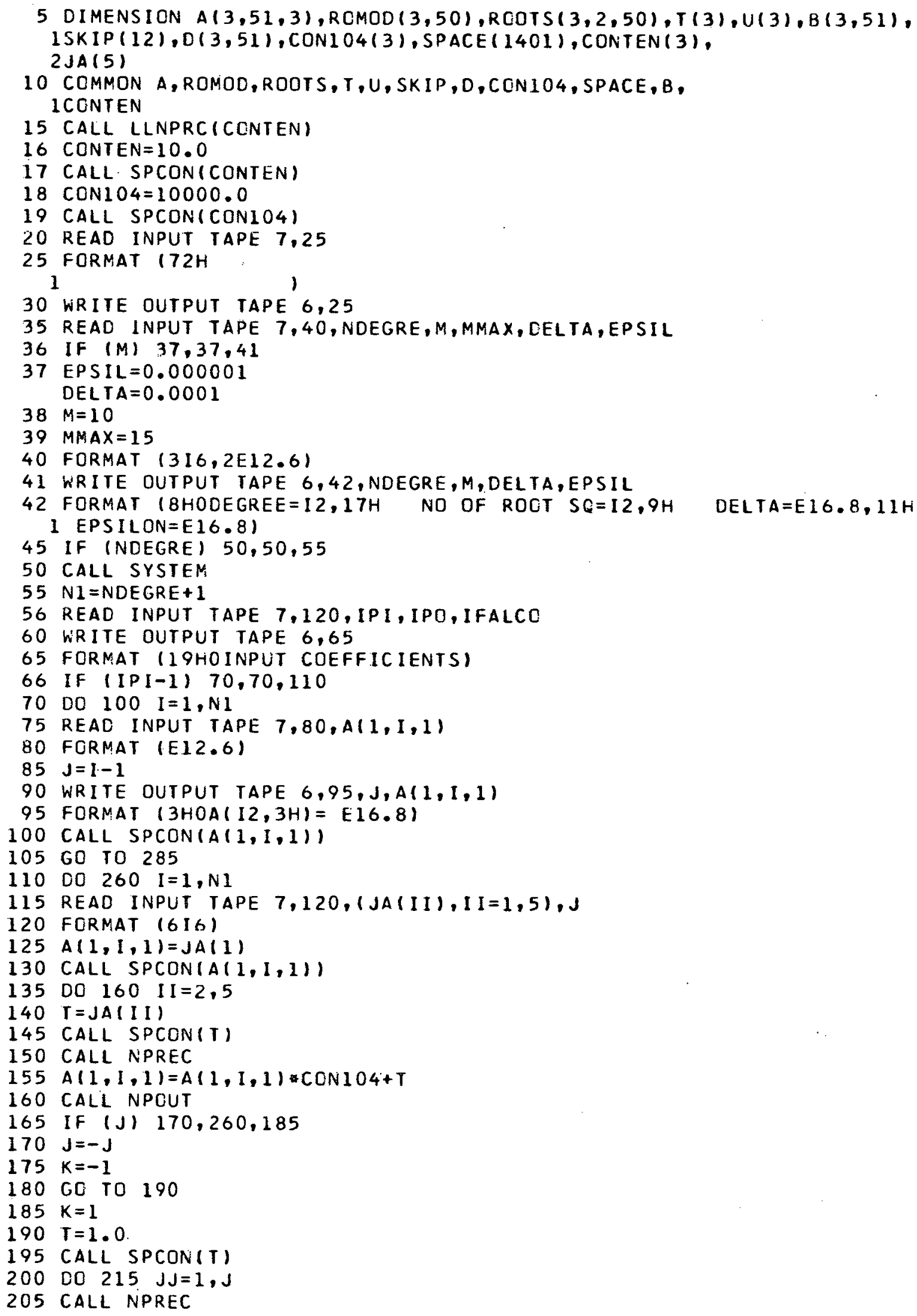




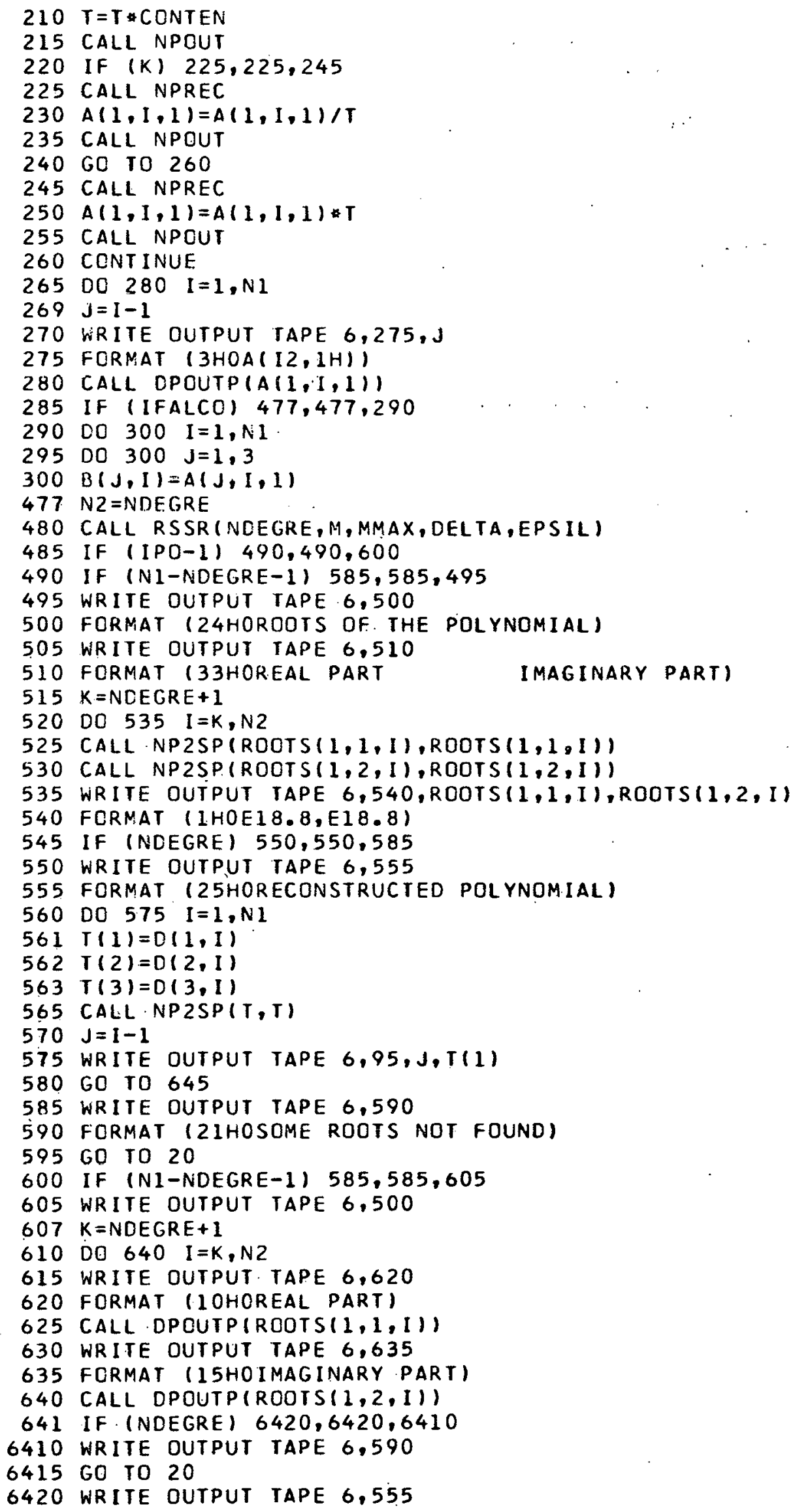




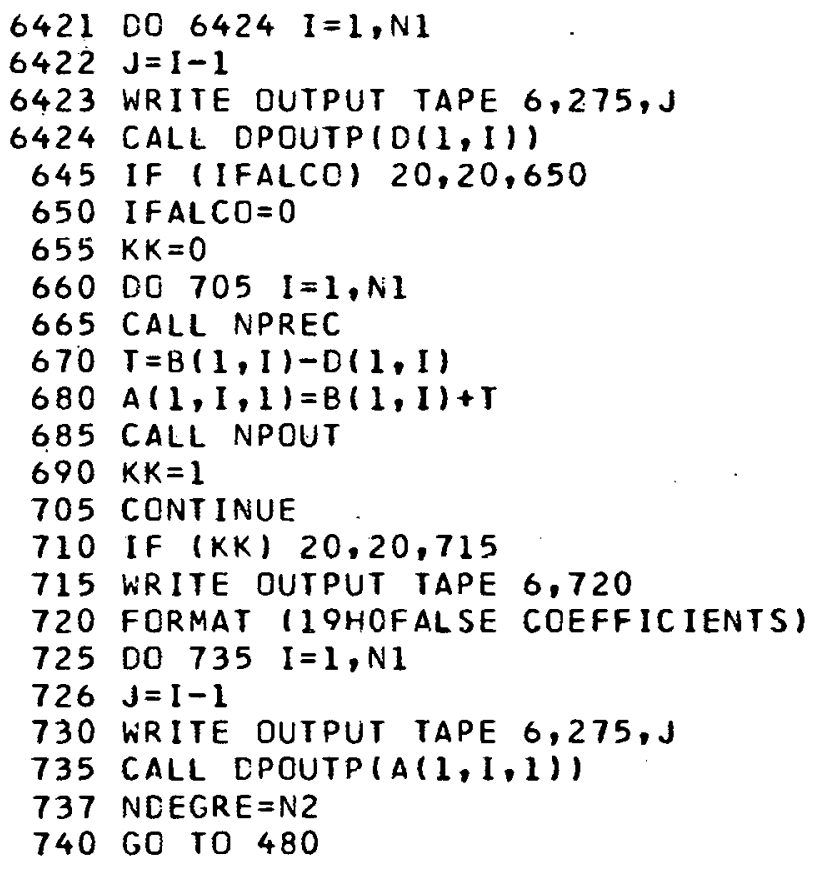


b. Subroutine RSSR

(Master subroutine: Checks for zero roots. Calls root-squaring subroutine, RTSQ. Calls subroutine for finding moduli of roots and finding real roots, RERO. If complex roots exist, it calls subroutine COMPRT to find them. Calls subroutine RECON to reconstruct the polynomial.)

3 SUBROUTINE RSSR (NDEGRE, M, MMAX, OELTA,EPSIL)

5 DIMENSION A $(3,51,3), \operatorname{ROMOC}(3,50), \operatorname{RCOTS}(3,2,50), \operatorname{CONO}(3), \operatorname{CON} 1(3)$, ICON2 (3), CON4 (3),T (3),U(3), D (3,51), SPACE $(1398), E(3)$, MROMOD $(50)$. 2NCNRT ( 50$)$, MNONRT (50), C (51), CON104(3), JA (4)

10 COMMON A, ROMOO, ROOTS, CONO, CON, CON2, CON4, T, U, D, CON1 04, SPACE, E

$S$ AA OCT 000000000000

$S$ BB OCT 000000000001

CC OCT 200000000000

CD OCT 000000000002

EE OCT 000000000003

$16(E N O(1)=A A$

$17 \operatorname{CONO}(2)=A A$

CONO $(3)=A A$

CONI $(1)=B B$

$18 \operatorname{CONI}(2)=C C$

$19 \operatorname{CCN} 1(3)=A A$

$\operatorname{CON} 2(1)=D D$

$\operatorname{CON} 2(2)=C C$

$\operatorname{CON} 2(3)=A A$

$\operatorname{CCN} 4(1)=E E$

$\operatorname{CON} 4(2)=C C$

$\operatorname{CON} 4(3)=A A$

$20 \mathrm{~N}=$ NEEGRE

36 IF (N) $37,37,45$

37 NDEGRE $=$ NCUR

38 RETURN

$45 \mathrm{~N} 1=\mathrm{N}+1$

$50 \quad \mathrm{~N} 2=\mathrm{N} 1+1$

55 DO $62 \quad I=1, N$

$56 K=N 2-I$

57 I F. $(A(2, K, 1)) 65,58,65$

$58 \mathrm{~J}=\mathrm{N} 1-\mathrm{I}$

59 CALL NPREC

$60 \operatorname{ROOTS}(1,1, J)=$ CONO

$61 \operatorname{ROOTS}(1,2, J)=$ CONO

62 CALL. NPOUT

63 NCEGRE $=0$

64 GO TO 38

$65 \mathrm{Nl}=\mathrm{K}$

$66 \mathrm{~N}=\mathrm{K}-1$

67 NCUR $=N$

$68 \mathrm{NL}=\mathrm{N}$

105 CALL RTSO (A,NCUR,M)

110 CALL REROIA,M,NCUR, DELTA,EPSIL, ROMOD, MRCMOD, NONRT, MNONRT, NCO, ROOTS 1)

114 IF (NCO) $195,195,115$

$115 \mathrm{~N} 1=\mathrm{NCUR}+1$

120 CALL COMPRT (M, MNONRT, NONRT, MROMOD,NCO, DELTA,EPSIL,NCUR)

125 If (NCUR) $195,195,130$

130 IF (NL-NCUR) $135,135,131$

$131 \mathrm{NL}=\mathrm{NCUR}$

132 GO TO 105

$135 M=M+1$

136 IF (MMAX-M) 175,105,105

$175 \mathrm{~N} 1=N C U R+1$

$180 \quad 60$ TO 37

195 CALL RECON(ROOTS, A, D, NDEGRE)

$200 \quad 60 \quad$ TO 37 
c. Subroutine RTSQ

(Root-squaring process)

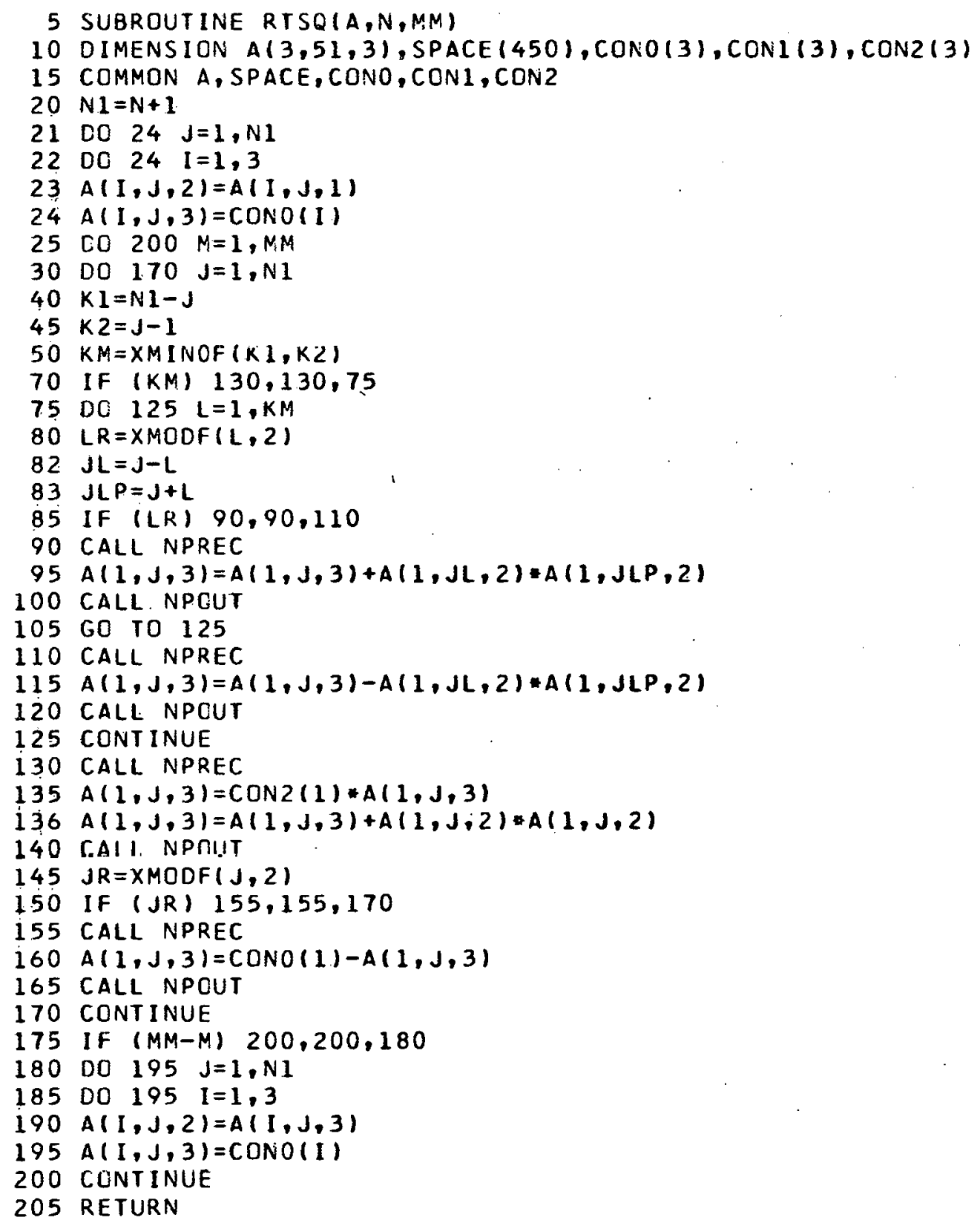




\section{d. Subroutine RERO}

(Finds moduli and real roots, calls for test subroutine, TEST)

5 SUBROUTINE RERO(A, M, NCUR, DELTA, EPSIL, ROMOD, MROMCD, NONRT, IMNONRT, NCO, ROOTSI

10 DIMENSION A $(3,51,3), R A T I O(50), T(3)$, IPIV $(50), R O M C D(3,50)$, MROMOC (50) $1, Q(3), W(3)$, ARED $(3,49)$, NONRT $(50)$, MNONRT $(50)$, SPACE.1 $(909), X N(3)$, 2ROOTS(3,2,50), CGNO(3), SPACE2 (933)

12 COMMON SPACE 1, CONO, SPACE2, T,Q, W, ARED,XN

$S$ MN OCT 000000000001

15 RATIOI $1=1.0$

16 If $(2$-NCUR) $20,20,82$

20 DO $65 \mathrm{I}=2$, NCUR

$2511=\operatorname{XMODF}(1,2)$

30 CALL NPREC

31 If $(A(1,1,3)) 35,32,35$

32 CALL NPOUT

33 RATIOI $I)=0.0$

34 GO TO 65

$35 T=A(1, I, 2): 2$

$36 T=T / A(1, I, 3)$

40 CALL NPOUT

45 CALL NP2SP (T. $(1), T(1))$

50 RATIOI $I)=T(1)$

55 IF (II) $65,60,65$.

60 RATIOII) =-RATIO(I)

65 CONTINUE

82 RATIOINCUR+1) $=1.0$

85 IPIV $(1)=1$

90 IPIV $(N C U R+1)=1$

91 IF (2-NCUR) $95,95,135$

95 DO $130 \quad I=2$, NCUR

$105 T(1)=A B S F(R A T I O(I)-2.0)$

110 IF (T(1)-DELTA) $115,125,125$

$115 \operatorname{IPIV}(I)=1$

120 GO TO 130

$125 \operatorname{IPIV}(I)=0$

130 CONTINUE

135 I $1=0$

140 MULT $=0$

$145 \quad I=1$

$150 \quad 14=1$

$155 \quad 11=11+1$

$160 \cdot 12=11+1$

165 MULT $=$ MULT +1

170 IF (IPIVII I )) $155,155,180$

180 CALL NPREC

$185 \operatorname{ROMOD}(1,14)=A(1, I 2,3) / A(1,1,3)$

190 IF(ROMOD $(1,14)) 195,200,200$

$195 \operatorname{ROMOD}(1,[4)=-R O M O D(1,14)$

200 CALL NPOUT

210 CALL CPLOG(ROMOD $(1,14), X N)$

$215 \quad M M=M$

5216 ARS 18

S 217 STO MM

S 218 CLA XN(1)

$S 219$ SUB MM

S 220 STO XNI1)

221 IF $(I 1-2) \quad 240,222,226$

S 222 CLA XN(1)

S 223 SUB MN

S 224 STO XN(1) 


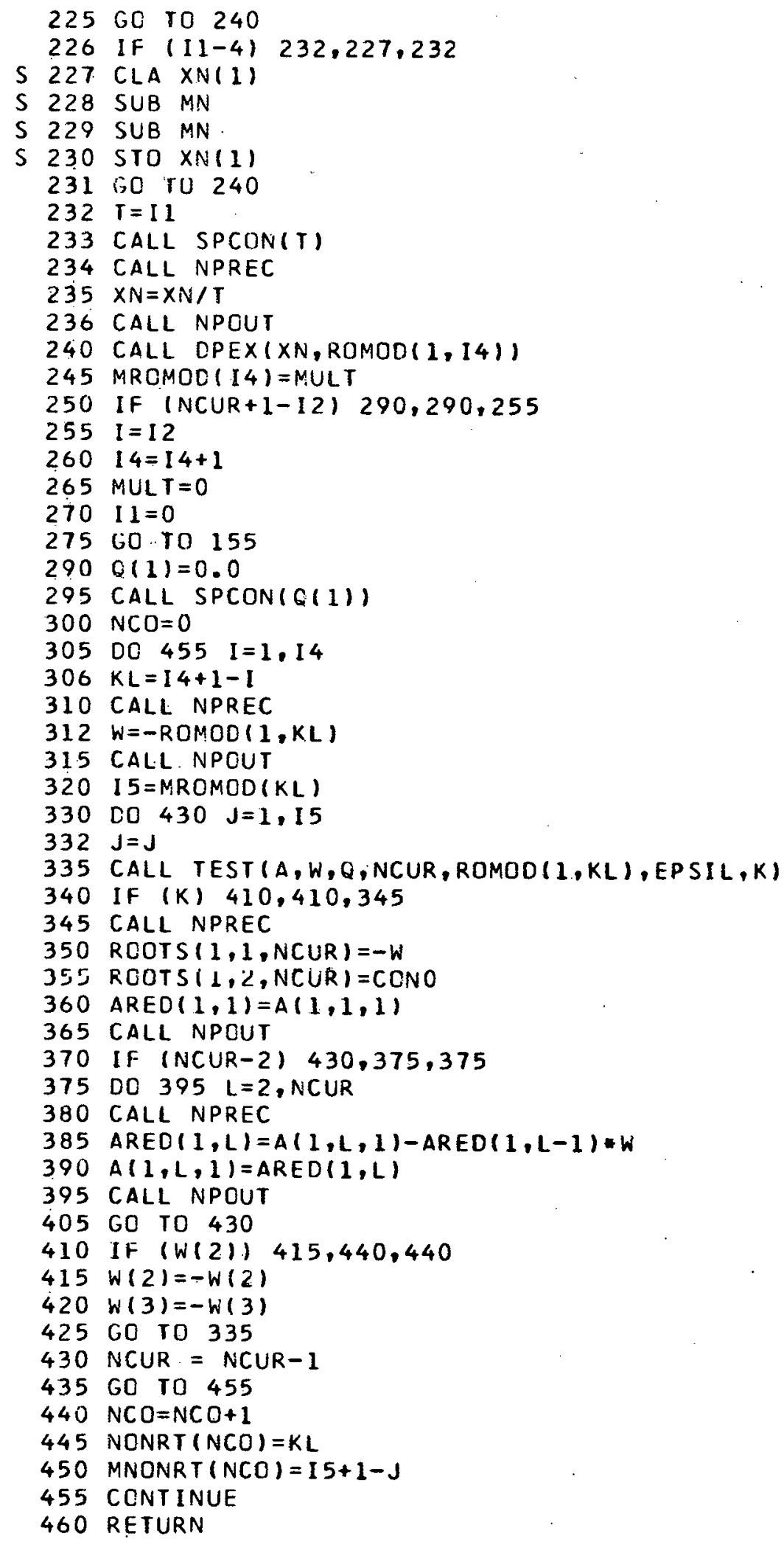


:e. Subroutine TEST

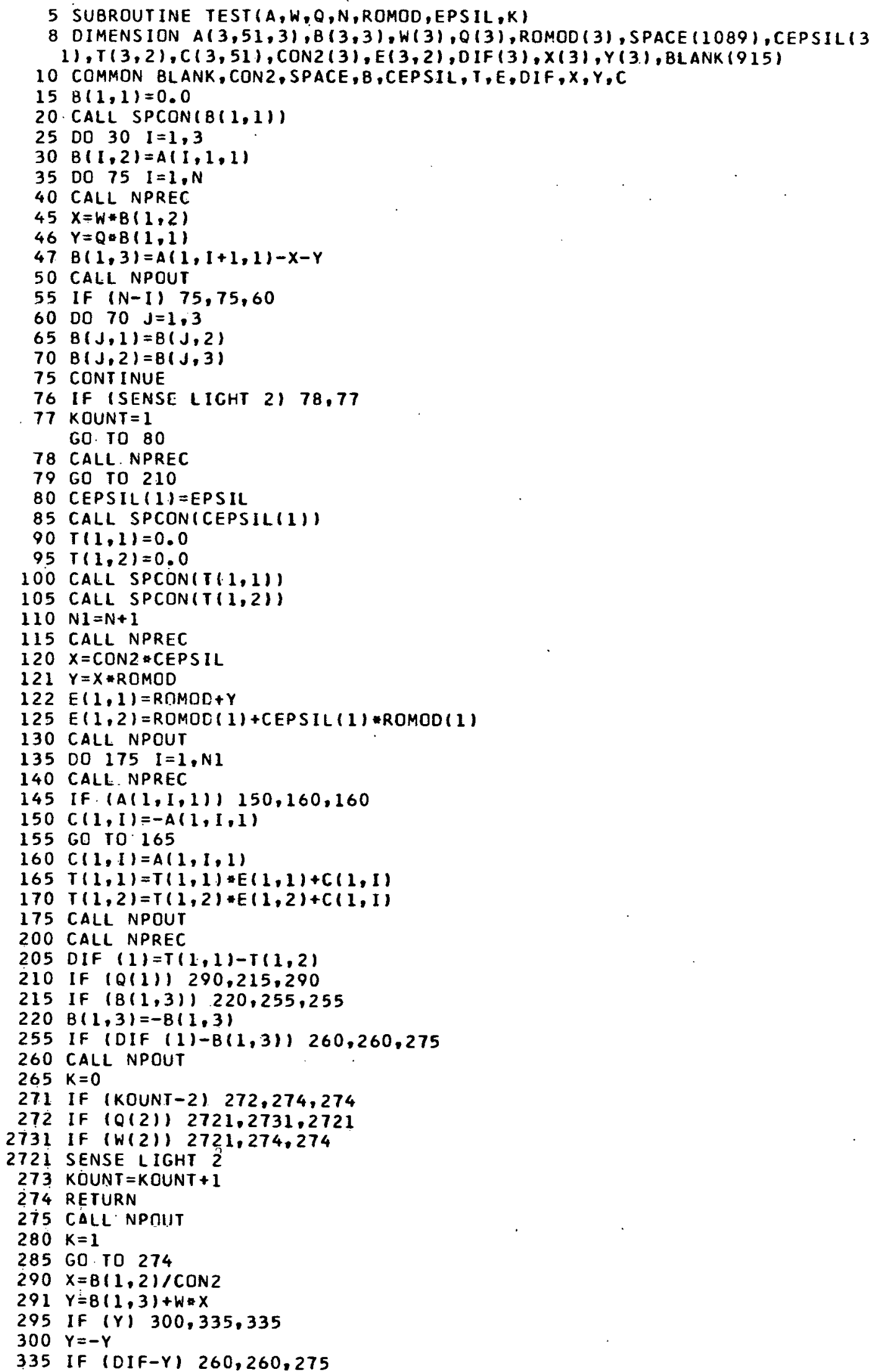




\section{f. Subroutine COMPRT}

(Finds complex roots and calls TEST)

5 SUBROUTINE COMPRT (MM, MNONRT, NONRT, MROMOD, NCO, DELTA, EPSIL, NCUR) 10 DIMENSION A $(3,51,3), \operatorname{ROMOD}(3,50), \operatorname{RCOTS}(3,2,50), \operatorname{CONO}(3), \operatorname{CON} 1(3)$, 1 CON $2(3), \operatorname{CON} 4(3), \operatorname{SR}(3,51,3), \operatorname{SROMOD}(3,50), \operatorname{SROCTS}(3,2,50), U(3), T(3)$, $2 W(3), Q(3), W E(3), A A(3), B B(3), R(3,2), D(3,2), B(3,49), \operatorname{MNONRT}(50)$, 3NONRT (50), MSROMD (50), NSONRT (49), MSNORT (49), MROMOD (50)

15 COMMON A, RONOD, ROOTS, CONO, CON1, CON2, CON4,SR, SROMOD, SROOTS,U, T, W,, , $I W E, A A, B B, R, D, B$

$2000295 \quad I=1, N C D$

22 JA =NONRT (I)

25 I $1=$ MNONRT $(1)$

$26 \quad I 1=I 1 / 2$

27 IF (II) $39,39,40$

39 I $1=1$

40 IF (ROMOD(2,JA)) $45,295,45$

$45 Q(1)=R O M O C(1, J A)$

$48 \quad Q(2)=\operatorname{ROMOD}(2, J A)$

$50 Q(3)=\operatorname{RUMOC}(3, J A)$

55 DO $290 \mathrm{~J}=1$, II

60 CALL SUBRESINCUR)

65 IF (NCUR-4) $67,67,72$

67. $N S C U R=1$

$68 \mathrm{~J} 2=1$

70 GO TO 80

72 NSCUR=NCUR-3

$73 \mathrm{~J} 2=\mathrm{NSCUR}$

$80 \mathrm{LL}=N S C U R+1$

113 IF (NSCUR-1) $305,305,115$

115 CALL RTSQ(SR, NSCUR, MM)

120 CALL REROISR, MM, NSCUR, DELIA, EPSIL, SROMOD, MSROMD, INSONRT, MSNORT, NSCO, SROOTS)

125 IF (J2-NSCUR) $126,126,140$

126. CALL NPREC

127 SROOTS $(1,1, J 2)=$ CONO

128 CALL NPOUT

140 CALL NPREC SROOT $S(1,1, J 2)=\operatorname{SROOTS}(1,1, J 2) \sharp R O M O D(1, J A)$

$145 T=C O N 2$ ROMOD $(1, J A)$

146 IF (SROOTS $(1,1, J 2)-T) \quad 165,150,150$

150 CALL NPOUT

155 GO TO 275

$165 W(1)=S R O O T S(1,1, J 2)$

167 WE $(1)=\operatorname{ROMOD}(1, J A) * 2$

169 CALL NPOUT

i 70 CALL TEST (A,W,WE, NCUR, ROMOD $(1, J A), E P S I L, K)$

175 IF (K) $255,255,180$

180 CALL NPREC

181 ROOTS $(1,1, N C U R)=-W / C O N 2$

$182 \mathrm{~T}=$ CON 4 *WE

$183 U=W * 2$

$184 \mathrm{~T}=\mathrm{T}-\mathrm{U}$

$185 U=D P S Q T(T)$

186 RCOTS $(1,2, N C U R)=U / C O N 2$

$190 \operatorname{ROOTS}(1,1, N C U R-1)=\operatorname{ROOTS}(1,1, N C U R)$

$195 \operatorname{ROOTS}(1,2, N C U R-1)=-R O O T S(1,2, N C U R)$

196 CALL NPOUT

200 DO $210 \quad 1 Q=1,3$

$205 D(1 Q, 1)=W(16)$

210 D $(I Q, 2)=W E(I Q)$

225 CALL GUADIV(NCUR) 


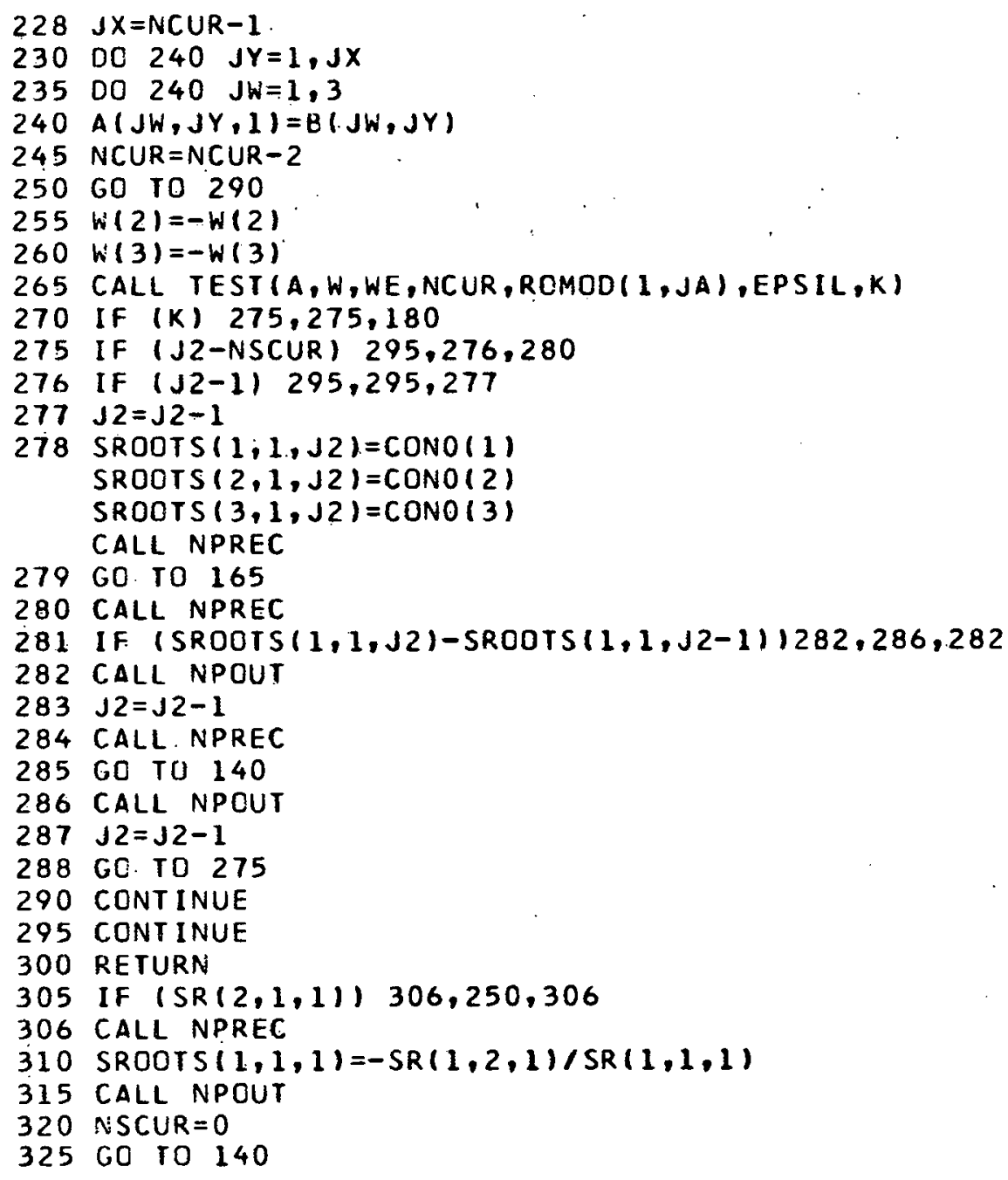


g. Subroutine SUBRES

(Constructs the reduced subresultant polynomial)

5 SUBROUTINE SUBRES(N)

10 DIMENSION A $(3,51,3), \operatorname{SPACE}(450), \operatorname{CON} 1(3), \operatorname{BLANK}(6)$, $1 S R(3,51,3)$, CPEN $(459), R O M O D(3), x(3), 1(3), C(3,51), U(3)$, $2 B(3,50,3), C O N O(3)$

15 COMMON A, SPACE, CONO, CONI, BLANK, SR, OPEN, ROMOD, $X, T, C, U, B$

$20 \mathrm{~N} 1=\mathrm{N}+1$

$25 \mathrm{~T}(1)=\operatorname{CON} 1(1)$

$30 \mathrm{~T}(2)=\operatorname{CON} 1(2)$

$35 T(3)=\operatorname{CON} 1(3)$

40 DC $65 \quad \mathrm{I}=1, \mathrm{~N}$

$45 \mathrm{~J}=\mathrm{N} I-\mathrm{I}$

50 CALL NPREC

$55 T=T$ ROMOD

$60 \quad(1, J)=A(1, J, 1): T$

65 CALI. NPCUT

$70 C(1, N 1)=A(1, N 1,1)$

$75 C(2, N 1)=A(2, N 1,1)$

$80 C(3, N 1)=A(3, N 1,1)$

84 IF $(N-2) \quad 260,260,85$

$85 \mathrm{~N} 2=\mathrm{N}-2$

90 DO $110 \quad \mathrm{I}=1, \mathrm{~N} 2$

95 CALL NPREC

$100 \mathrm{~B}(1,1,1)=$ CONO

105 B $\{1,1,2\}=$ CONO

110 CALL NPQUT

$115 \mathrm{I}=2$

$120 \quad B(1,1,2)=C(1,1)$

$125 \quad B(2,1,2)=C(2,1)$

$130 B(3,1,2)=C(3,1)$

135 CALL NPREC

i $40 \quad B(1,1,3)=C(1,1)-B(1,1,1)$

145 CALL NPOUI

150 DC $165 \mathrm{~J}=2, \mathrm{~N} 2$

155 CALL NPREC

$160 \quad B(1, J, 3)=-B(1, J-1,2)-B(1, J, 1)$

165 CALL NPOUT

170 IF $(N-3-I) \quad 205,175,175$

$175 \quad I=I+1$

180 DC $195 \mathrm{~J}=1, \mathrm{~N} 2$

185 DO $195 \mathrm{~K}=1,3$

$190 B(K, J, 1)=B(K, J, 2)$

$195 \quad B(K, J, 2)=B(K, J, 3)$

200 GC TO 135

205 CALL NPREC

$210 S R(1, N 2,1)=C(1, N)-B(1,1,3)$

$215 S R(1, N 2-1,1)=-C(1, N 1)-B(1,2,3)$

220 CALL NPCUT

222 IF (N2-2) $245,245,225$

225 DC $240 \mathrm{~J}=3, \mathrm{~N} 2$

$228 K=N 2+1-J$

230 CALL NPREC

$235 \mathrm{SR}(1, \mathrm{~K}, 1)=-\mathrm{E}(1, \mathrm{~J}, 3)$

240 CALL NPCUT

245 RETURN

260 CALL NPREC

$265 \operatorname{SR}(1,1,1)=C(1,1)$

$270 \operatorname{SR}(1,2,1)=-C(1,2)$

275 CALL NPOUT

280 GO TO 245 


\section{h. Subroutine RECON}

(Reconstructs the original polynomial from the computer zeros)

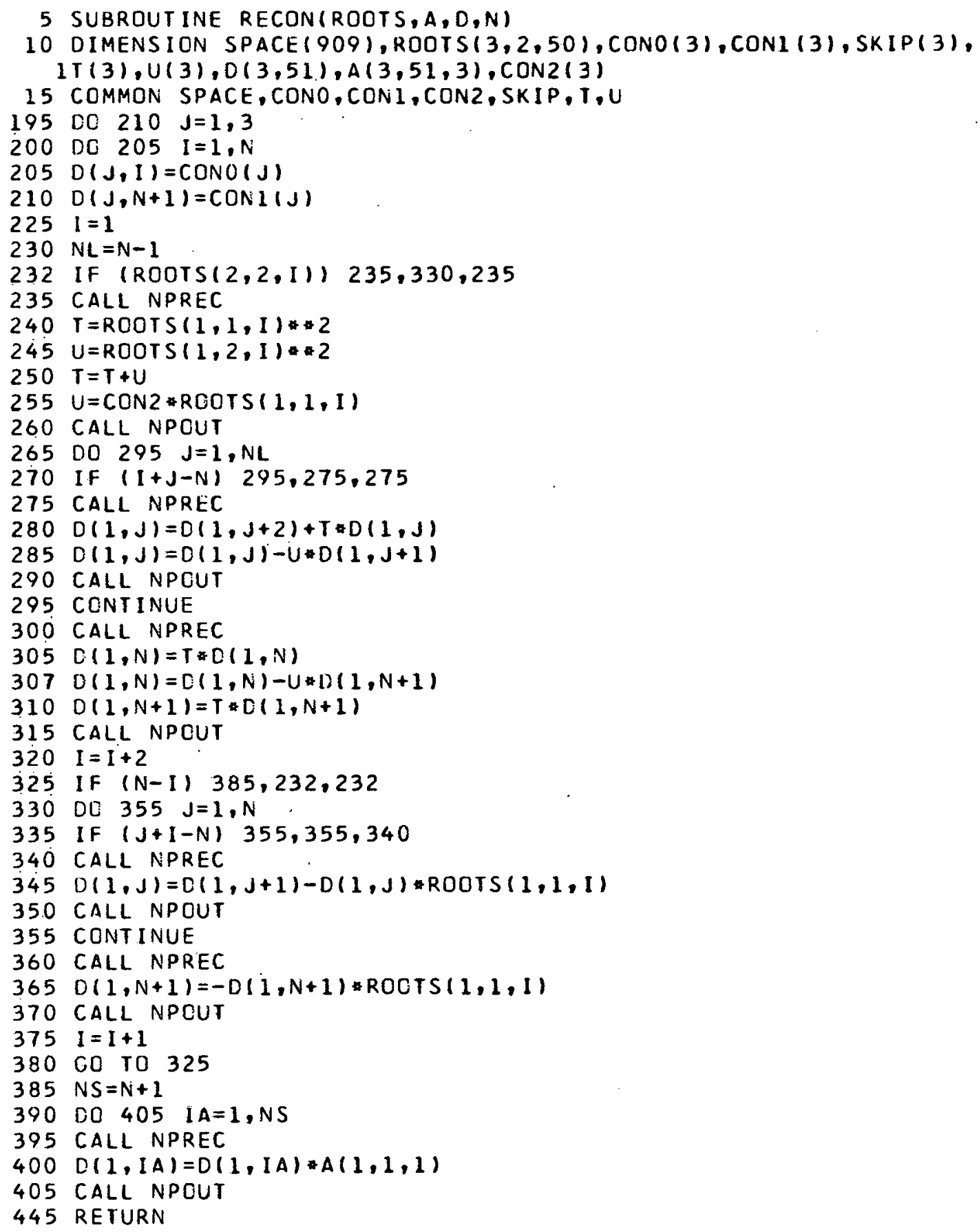




\section{i. Subroutine QUADIV}

(Divides out quadratic factors)

5 SUBROUTINE GUADIV(N)

10 DIMENSION $A(3,51,3), \operatorname{SPACE}(1392), R(3,2), D(3,2), B(3,49), X N(3), Y N(3)$

12 COMMON A,SPACE,R,D,B,XN,YN

15 CALL NPREC

$20 B(1,1)=A(1,1,1)$

21 CALL NPOUT

22 IF $(N-2) \quad 60,60,23$

23 CALL NPREC

$25 \quad B(1,2)=A(1,2,1)-B(1,1)=D(1,1)$

26 CALL NPOUT

30 IF $(N-3) \quad 60,60,35$

$35 \mathrm{NT}=\mathrm{N}-1$

$400055 \cdot I=3, N \mathrm{~N}$

45 CALL NPREC

$50 X N=B(1, I-1) \approx D(1,1)$

$51 Y N=B(1,1-2) * D(1,2)$

$52 B(1, I)=A(1, I, 1)-X N-Y N$

55 CALL NPOUT

60 CALL NPREC

$65 X N=B(1, N-1) * D(1,1)$

$66 Y N=B(1, N-2) \approx D(1,2)$

$67 R(1,1)=A(1, N, 1)-X N-Y N$

$70 R(1,2)=A(1, N+1,1)-B(1, N-1) * D(1,2)$

72 CALL NPGUT

75 RETURN 


\section{j. Subroutine DPOUTP}

(Outputs double-precision numbers)

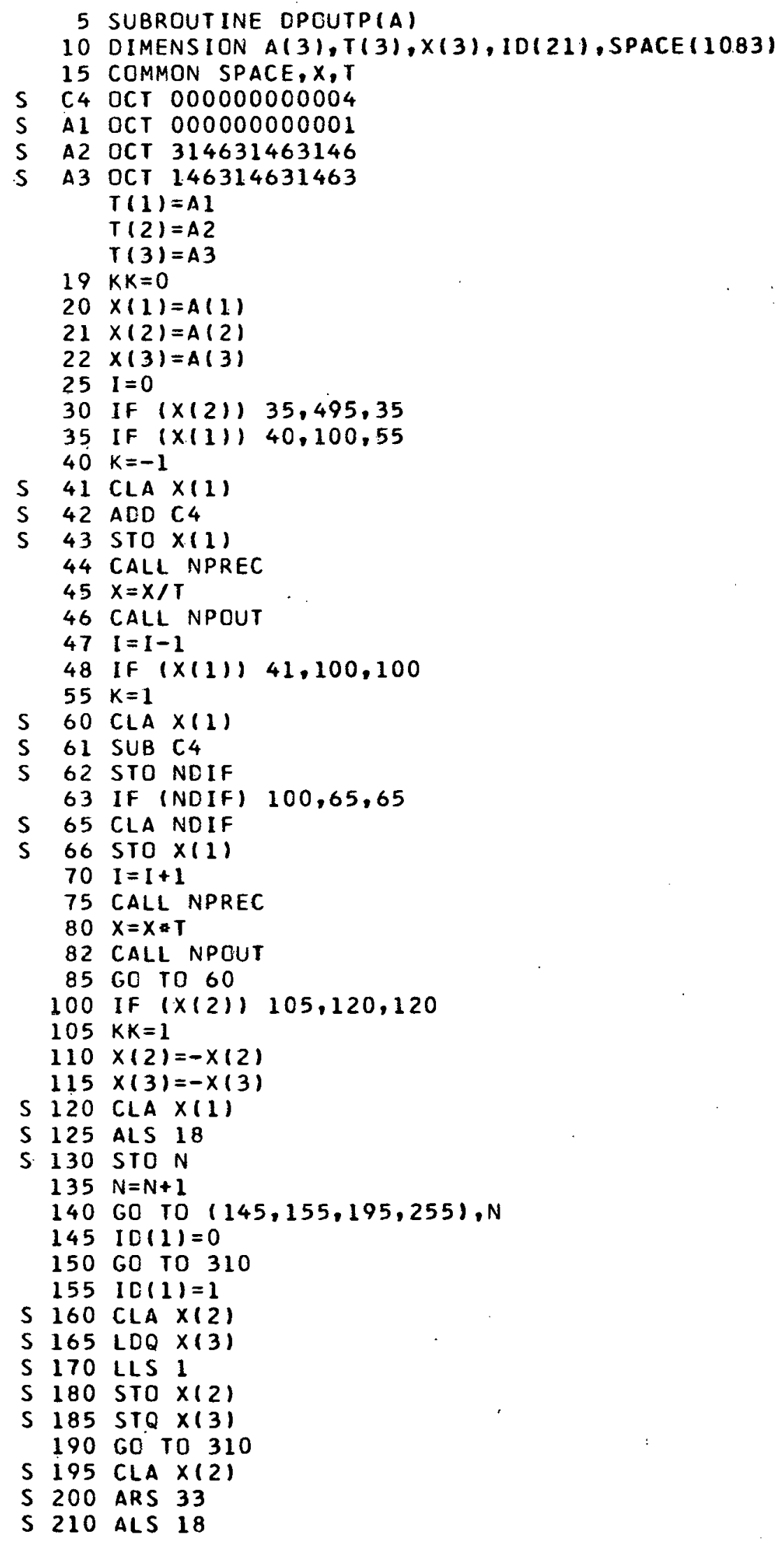




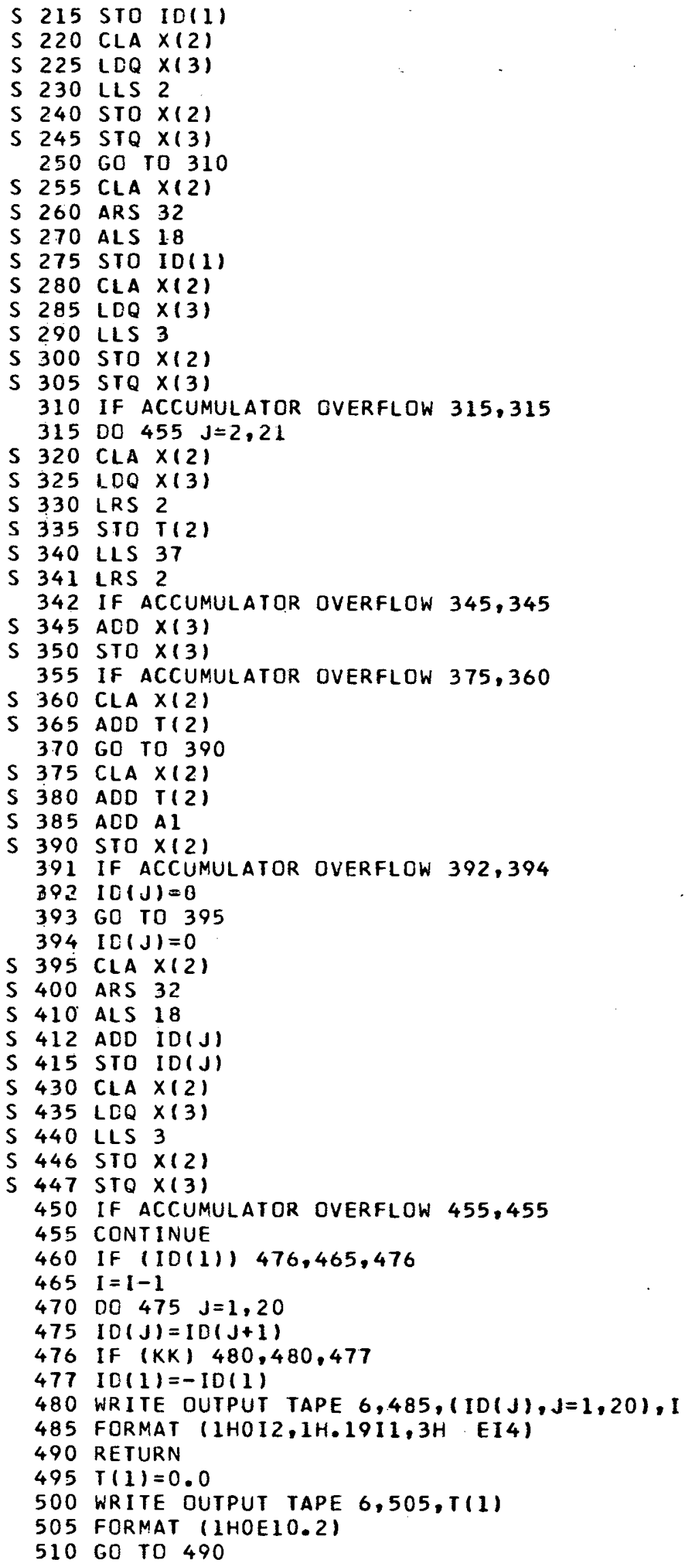




\section{k. Subroutine SPCON}

(Converts single-precision floating-point numbers to double precision).

5 SUBROUTINE SPCONIIA)

10 DIMENSION IAI3)

15 I $A(2)=0$

20 IA $(3)=0$

S $25 \mathrm{CLM}$

S 30 LCQ IA (1)

$S 35$ LLS 0

$S 40$ STO IA(3)

545 LLS 8

$S 50$ SSP

$S 55$ STO [A(1)

$S 60$ STQ IA(2)

$65 I=1$

S 70 ARS 11

$S 75$ STO I

80 IF (IAII)) $85,90,85$

$85 I A(1)=I A(1)-I$

90 RETURN 
1. Subroutine DPEX

(Computes $\mathrm{e}^{\mathrm{x}}$ in double precision for double-precision $\mathrm{x}$ )

5 SUBRDUTINE DPEX $(X, Y)$

10 DIMENSION SPACE (912), CON1 (3), BLANK(1092), X(3),Y(3), TEST(3), TEMP(3)

1, EF(3), T (3), R(3),Z(3),U(3), FAC (3), E(3)

15 COMMON SPACE, CON $1, B L A N K, T E S T, T E M P, T, R, Z, U, F A C, E F, E$

$S$ EI DCT 000000000000

$S$ E2 OCT 261344137676

$S$ E3 DCT 216367465365

$S$ F1 OCT 000000000013

$S$ F2 OCT 200000000000

$E F(1)=E 1$

$E F(2)=E 2$

$E F(3)=E 3$

20 IF $(X(2)) \quad 25,45,45$

$25 k=1$

$30 \mathrm{~T}(2)=-x(2)$

$35 T(3)=-x(3)$

40 go ro 60

$45 \quad T(2)=x(2)$

$50 \quad T(3)=x(3)$

$55 \mathrm{~K}=0$

$60 T(1)=x(1)$

65 CALL NPREC

66 TEMP $=$ CON 1

$70 R=T / E F$

75 CALL NPOUT

80 CALL NP2SP $(R, R)$

85 I $Q=R$

$90 U=10$

95 CALL SPCON(U)

100 CALL NPREC

105 TEST $=U \sharp E F$

110 IF (T-TEST) $115,140,140$

$115 U=U-C O N 1$

120 TEST $=U * E F$

125 CALL NPCUT

$130 \quad 1 Q=1 Q-1$

135 CALL NPREC

$140 \mathrm{~T}=\mathrm{T}-\mathrm{TEST}$

145 CALL NPOUT

$150 I Q Q=I Q / 10$

$155 I Q=I Q-I Q Q * 10$

$160 \mathrm{~J}=2 * I Q$

$161 E F(1)=\operatorname{CON} 1(1)$

$162 E F(2)=\operatorname{CON} 1(2)$

$163 \mathrm{EF}(3)=\operatorname{CON} 1(3)$

$164 U(1)=F 1$

$165 U(2)=F 2$

$166 U(3)=F 3$

167 IF (IQQ) $180,180,168$

168 DO $171 \quad I=1, I Q Q$

169 CALL. NPREC

$170 \quad E F=E F * U$

171 CALL NPOUT

$180 \quad 2=J$

185 CALL SPCON(Z)

190 CALL NPREC

$195 E=Z * E F$

$205 \mathrm{Z}=\mathrm{CON} 1$

210 CALL NPOUT 


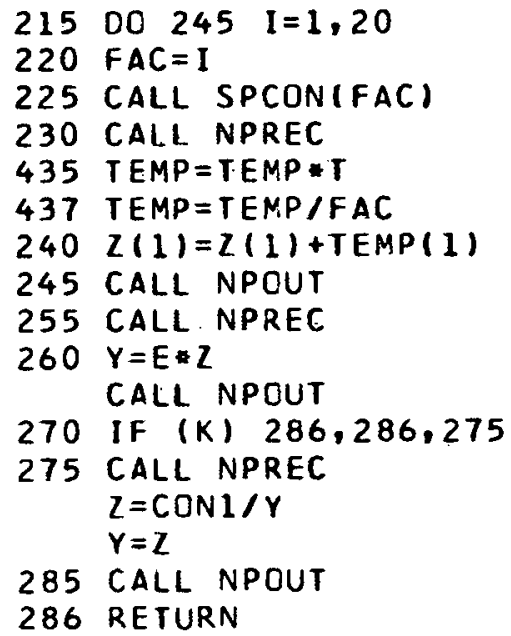

286 RETURN 
m. Subroutine DPLOG

(Computes double-precision natural logs for double-precision arguments)

5 SUBROUTINE CPLOG $(A, A L)$

10 DIMENSION A(3), CONI $(3), \operatorname{CON} 2(3), X(3), Y(3), 2(3), U(3), A L(3), V(3), W(3)$ 1, , C (3), SPACE (909), BLANK $(1089)$, CONO(3).

15 COMMON SPACE, CONO,CON $1, C O N 2, B L A N K, X, Y, Z, U, V, W, D C$

$S \quad M$ OCT 000000000001

$S \quad C$ OCT 261344137676

$S$ D OCT 216367465366

$45 \mathrm{~T}=\mathrm{A}(1)$

$50 A(1)=0.0$

55 CALL NPREC

$57 Y=A-C O N 1$

$602=A+C O N 1$

$62 X=Y / Z$

65 CALL NPQU,

$66 \quad A(1)=T$

70 DO $80 \quad I=1,3$

$75 \quad Y(1)=x(1)$

$802(I)=X(I)$

81 CALL NPREC

$82 V=X * 2$

83 CALL NPOUT

85 DO $115 \quad I=2,14$

$90 \cup(1)=F L O A T F(I)$

95 CALL SPCON(U11))

100 CALL NPREC

$102 Y=Y * V$

$103 U=\operatorname{CON} 2 * U$

$104 O C=U-C O N 1$

$105 h^{\prime}=Y / D C$

$106 Z=Z+W$

115 CALL NPOUT

120 CALL NPREC

$121 \quad r=C O N O$

$122 Z-\operatorname{CON} 2 * L$

123 CALL NPOUT

$130 \times(1)=$ CONO $(1)$

$135 \times(2)=\mathrm{C}$

$140 \times(3)=0$

145 If $(A(1)) \quad 150,225,150$

$150 \mathrm{~N}=\mathrm{M}$

155 D0 $220 \quad I=1,35$

$S 160$ CLA A(1)

$S 165$ ANA $N$

S 170 STO R

175 IF (R) $180,195,180$

180 CALL NPREC

185 $Y(1)=Y(1)+X(1)$

190 CALL NPOUT

195 CALL NPREC

$200 \times(1)=\operatorname{CON} 2(1) * \times(1)$

205 CALL NPOUT

S 210 CLA N

$S 215$ ALS 1

S 220 STO N

221 IF $(A(1)) \quad 245,225,225$

225 CALL NPREC

$230 \mathrm{AL}(1)=2(1)+Y(1)$

235 CALL NPOUT

240 GO TO 260

245 CALL NPREC

$250 \quad A L=Z-Y$

255 CALL NPCUT

260 RETURN 
2. FORTRAN 63 Statements of the RSSR Routine as Coded for the CDC-3600 Computer

a. Main Program

(Does input and output, and calls RSSR)

b. Subroutine RSSR

(Calls subroutines for root squaring, finding moduli of roots and real roots, finding complex roots, and reconstructing the polynomial)

c. Subroutine ROOTSQ

(Performs the root squarings)

d. Subroutine REALROOT

(Finds moduli of roots and real roots)

e. Subroutine COMPROOT

(Finds the complex roots)

f. Subroutine TEST

(Tests roots for accuracy)

g. Subroutine SUBRES

(Computes reduced subresultant polynomial or, if $n=4$, the subresultant polynomial)

h. Subroutine RECON

(Reconstructs the polynomial from the roots and the first coefficient)

i. Subroutine QUADIV

(Divides out quadratic factors)

j. Subroutine DOUBLOG

(Computes double-precision log for numbers of the form $x$ times $64^{I x}$ )

k. Subroutine DOUBLEXP

(Computes in double precision $e^{t}$, where $t=x\left(64^{I x}\right)$ ) 
1. Subroutine ADD

(Adds numbers of the form $\mathrm{x}\left(64^{\mathrm{Ix}}\right)$ and $\mathrm{y}(64 \mathrm{Iy})$, where $\mathrm{x}$ and $\mathrm{y}$ are in double precision)

m. Subroutine SUBTRACT

(Subtracts numbers of the form $\mathrm{x}\left(64^{\mathrm{Ix}}\right)$ and $\mathrm{y}(64 \mathrm{Iy})$, where $\mathrm{x}$ and $\mathrm{y}$ are in double precision)

n. Subroutine SCALE

(Scales double-precision numbers of the form $x$ times $64^{\mathrm{Ix}}$ so that $1 / 64 \leq 1|x| 1 \leq 64(x \neq 0)$

o. Subroutine UNSCALE

(Unscales numbers of the form $x\left(64^{\mathrm{Ix}}\right)$ to the form $\bar{X}\left(64^{\overline{\mathrm{Ix}}}\right)$ such that $\overline{I_{x}}=0$ ) 
a. Main Program

(Does input and output, and calls RSSR)

C

PROGRAM RSSRMAIN

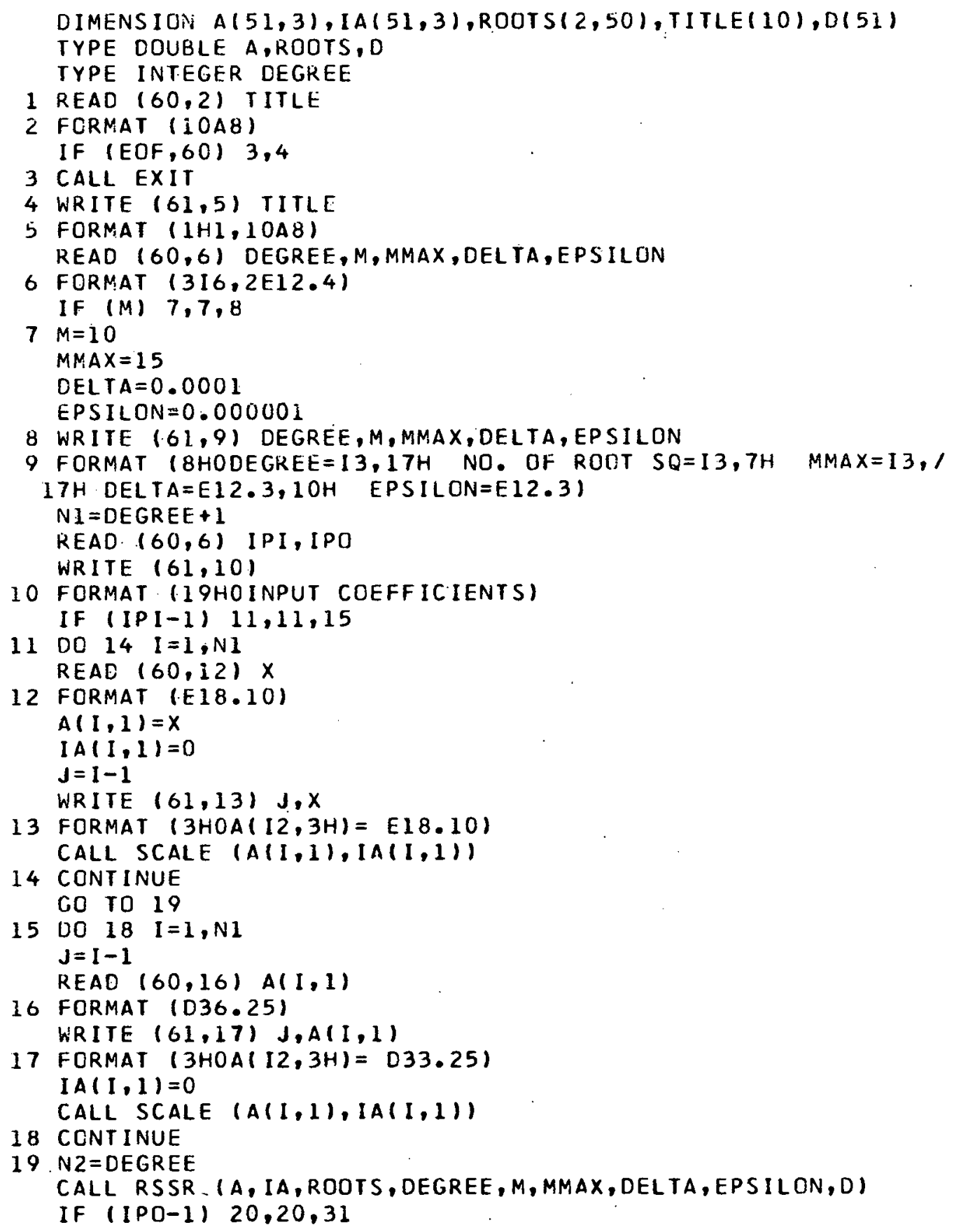




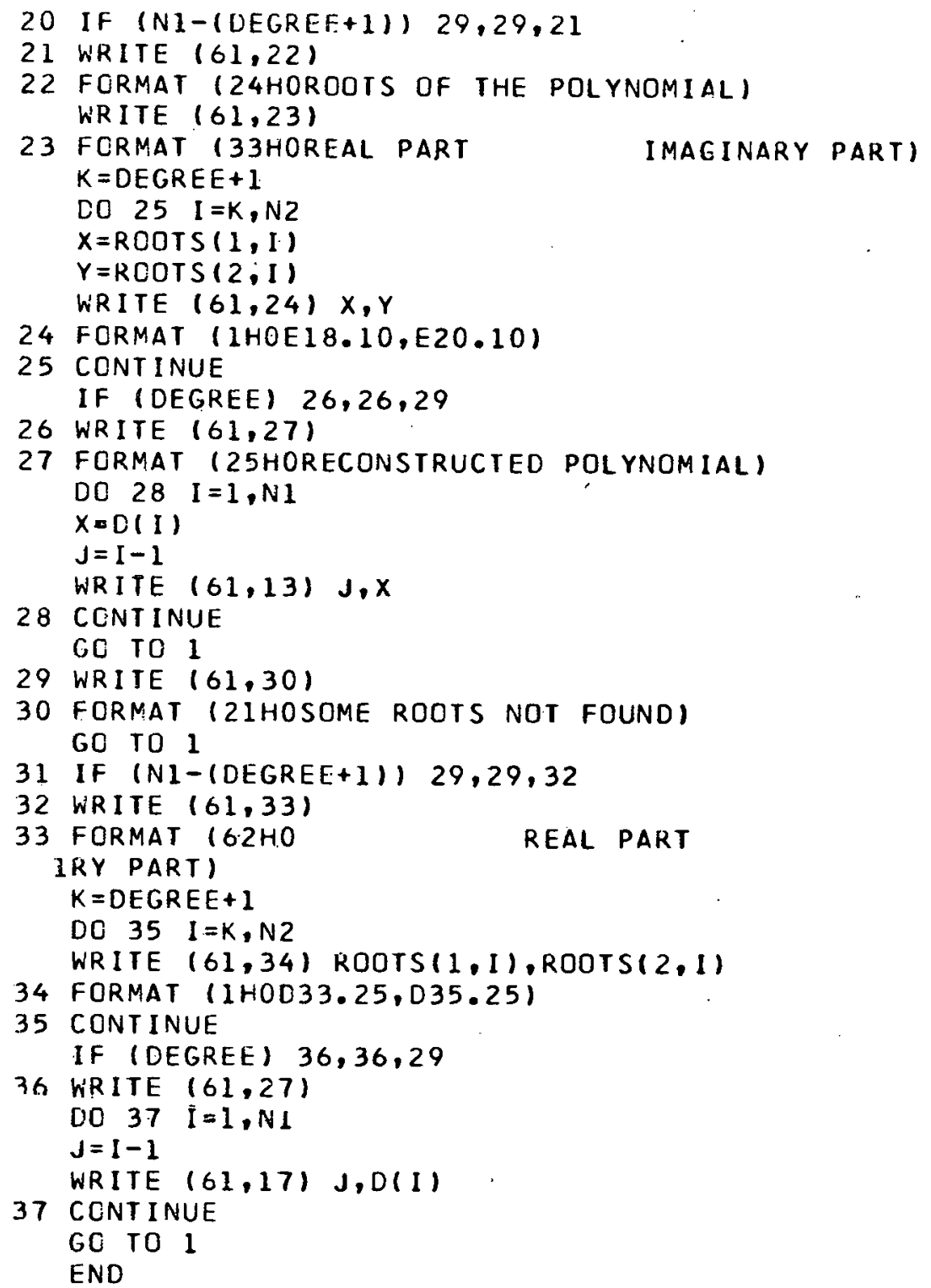

I MAG INA 


\section{b. Subroutine RSSR}

(Calls subroutines for rootsquaring, finding moduli of roots and real roots, finding complex roots, and reconstructing the polynomial)

C

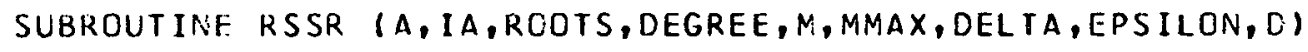

DIMENSION A(51,3), IA $(51,3), \operatorname{ROOTS}(2,50), D(51), \operatorname{ROMOO}(50), \operatorname{MROMOD}(50)$, INCNRT (50), MNONRT (50)

TYPE COUBLE A,ROOIS,D,ROMOD

TYPE INTEGER DEGREE

$N=$ DEGREF.

If (N) $1,1,3$

1 DEGREE $=$ NCUR

2 RETURN

$3 \mathrm{Nl}=\mathrm{N}+1$

$\mathrm{N} 2=\mathrm{N} 1+1$

CC $5 \quad I=1, N$

$K=N 2-I$

IF $(A(K, 1)) 6,4,6$

$4 \mathrm{~J}=\mathrm{N} 1-\mathrm{I}$

$\operatorname{ROOTS}(1, J)=0.0$

$\operatorname{ROOTS}(2, J)=0.0$

5. CONTINUE

DEGREE $=0$

GO TO 2

$6 \mathrm{Nl}=\mathrm{K}$

$N=K-1$

$N C U R=N$

$N L=N$

7 CALL ROOTSQ (A, IA,NCUR,M)

CALL REALROCT (A, IA,M, NCUR, DELTA,EPSILON, ROMOD, MROMOD, INONRT, MNONRT, NCO, ROOTS)

IF (NCO) $12,12,8$

$8 \mathrm{~N} 1=N C U R+1$

CALL COMPROOT (A, IA, ROMOD, ROOTS, M, MNONRT, NONRT, IMROMOD, NCO, DELTA, EP.SI LON, NCUR I

IF (NCUR) $12,12,9$

9 IF (NL-NCUR) $11,11,10$

$10 \mathrm{NL}=\mathrm{NCUR}$

GO TO 7

$11 M=M+1$

IF (MMAX-M) $1,7,7$

12 CALL RECON (ROOTS,A $(1,1)$, IA $(1,1), C$, CEGREE)

GO TO 1

END 
c. Subroutine ROOTSQ

(Performs the root.squarings)

C

SUBRDUTINE ROOTSQ (A, IA, NCUR, MM)

DIMENSION $A(51,3), I A(51,3)$

TYPE DOUBLE $A, X$

$N 1=N C U R+1$

CO I $J=1, N 1$

$A(J, 2)=A(J, 1)$

IA $(J, 2)=1 A(\mathrm{~J}, 1)$

$A(J, 3)=0.0$

$[A(J, 3)=0$

1 CONTINUE

DO $9 M=1, N M$

$D O 6 \mathrm{~J}=1, \mathrm{NL}$

$\mathrm{K} 1=\mathrm{N} 1-\mathrm{J}$

$K 2=J-1$

$K M_{1}=X M I N O F(K 1, K 2)$

DO $4 \mathrm{~L}=1, K M$

$L R=X M O D F(L, 2)$

$J L=J-L$

$J L P=J+L$

IF (LR) $2,2,3$

$2 X=A(J L, 2) * A(J L P, 2)$

$I X=I A(J L, 2)+I A(J L P, 2)$

CALL SCALE $(X, I X)$

CALL ADD $(A(J, 3), I A(J, 3), X, I X, A(J, 3), I A(J, 3))$

GC TO 4

$3 X=A(J L, 2) * A(J L P, 2)$

$I X=I A(J L, 2)+I A(J L P, 2)$

CALL SCALE $(X, I X)$

CALL SUBTRACT $(A(J, 3), I A(J, 3), X, I X, A(J, 3), I A(J, 3))$

4 CONTINUE

$A(J, 3)=2.0 * A(J, 3)$

CALL SCALE $(A(J, 3), I A(J, 3))$

$X=A(J, 2) \approx 2$

$I X=I A(J, 2)+I A(J, 2)$

CALL SCALE $(X, I X)$

CALL ADD $(A(J, 3), I A(J, 3), X, I X, A(J, 3), I A(J, 3))$

$J R=X M O D F(J, 2)$

IF (JR) $5,5,6$

$5 \quad A(J, 3)=-A(J, 3)$

6 CONTINUE

IF $(M M-M) \quad 9,9,7$

7 DO 8 J $=1, N I$

$A(J, 2)=A(J, 3)$

IA $(J, 2)=I A(J, 3)$

$A(J, 3)=0.0$

I $A(J, 3)=0$

8 CONTINUE

9 CONTINUE

REIURN

END 
d. Subroutine REALROOT

(Finds moduli of roots and real roots)

SUBROUTINE REALROOT IA, IA,M,NCUR, CELTA,EPSILON,ROMOD, MROMCD, INONRT, MNONRT, NCO, ROOTSI

C

DIMENS ICN A $(51,3),[A(51,3), \operatorname{ROOTS}(2,50), \operatorname{ROMOD}(50), \operatorname{MROMOD}(50)$, INONRT (50), MNONRT (50), RATIOI 51 ), I PIV (51), ARED (50), I ARED (50)

TYPE DOUBLE A,ROOTS, ROMOD,T,XN, $W, A R E O, Y, Q$

RATIOI 1$)=1.0$

DO $4 \quad I=2, N C U R$

$11=X \operatorname{MODF}(I, 2)$

IF $(A(I, 3)) 2,1,2$

1 RATIOI I $)=0.0$

GO TO 4

$2 T=A(1,2) \geqslant A(I, 2)$

$I T=I A(I, 2)+I A(I, 2)$

CALL SCALE (T.IT)

$T=T / A(1,3)$

$I T=I T-I A(I, 3)$

IF $(I T-2) \quad 50,50,1$

50 IF $(I T+2) \quad 1,51,51$

51 CALL UNSCALE (T, IT)

RATIO $(I)=T$

IF (II) $3,3,4$

3 RATIOII I=-RATIO(I)

4 CONTINUE

RATIO(NCUR+1) $=1.0$

IPIV $(1)=1$

$I P I V(N C U R+1)=1$

DO $7 \quad I=2$, NCUR

$X=A B S F(R A T I O(1)-1.0)$

IF $(X$-DELTA $5,6,6$

5 I $P$ IVI I ) $=1$

GO TO 7

6 I PIVII) $=0$

7 CONTINUE

NCUR $1=$ NCUR +1

I $\mathrm{I}=0$

MULT $=0$

$I=1$

$14=1$

$8 \quad 11=11+1$

$12=I 1+1$

MULT $=$ MULT $T+1$

IF (IPIVII $)$ ) $8,8,9$

9 ROMOD $(14)=A(12,3) / A(1,3)$

$I R O M O D=I A(I 2,3)-I A(I, 3)$

CALL SCALE (ROMOD(14), IROMOD)

IF (ROMOD(I4)) $10,11,11$

$10 \operatorname{ROMOD}(\mathrm{I} 4)=-\operatorname{ROMOO}(14)$ 
11 CALL DOUBLOG (ROMOD(I 4 ), IROMOD, XN, I XN)

$T=2.0 * M * I I$

$X N=X N / T$

CALL SCALE (XN, IXN)

CALL DOUBLEXP (XN, IXN,ROMOD(I4), IROMOD)

IF (IROMOD-150) $100,100,101$

100 IF (IRONOD+150) $101,101,102$

$101 \operatorname{ROMOD}(I 4)=0.0$

I ROMOD $=0$

GO TO 103

102 CALL UNSCALE (ROMOD(I4), IROMOD)

103 MROMOD $([4)=$ MULT

IF $(N C U R+1-12) \quad 13,13,12$

$121=12$

$14=14+1$

MULT $=0$

I $1=0$

GO TO 8

$13 Q=0.0$

$\mathrm{NCO}=0$

UO $22 \quad I=1,14$

$K L=I 4+I-I$

$W=-R O M O C(K L)$

I $5=$ MROMOD $(K L)$

DC $20 \mathrm{~J}=1, \mathrm{I} 5$

$\mathrm{J}=\mathrm{J}$

14 CALL TEST $(A, I A, W, Q, N C U R, R O M O D(K L), E P S I L O N, K)$

IF (K) $17,17,15$

15 ROOTS $(1, N C U R)=-W$

R.OOTS $(2, N C U R)=0.0$

$\operatorname{ARED}(1)=A(1,1)$

IARED $(1)=I A(1,1)$

DO $16 L=2$, NCUR

$Y=A R E D(L-1) * W$

I $Y=$ I AREC $(L-1)$

CALL SCALE $(Y, I Y)$

CALL SUBTRACT $(A(L, 1), I A(L, 1), Y, I Y, A R E D(L), I A R E D(L))$

$A(L, 1)=A R E D(L)$

$I A(L, I)=I A R E D(L)$

16 CONTINUE

GO TO 19

17 IF (W) $18,21,21$

is $W=-W$

GO TO 14

19 NCUR = NCUR-1

20 CONT INUE

GO TO 22

$21 N C O=N C O+1$

NONRT $(N C O)=K L$

MNONRT $(N C O)=15+1-J$

22 CONTINUE

RETURN

END 


\section{e. Subroutine COMPROOT}

(Finds the complex roots)

SUBROUTINE COMPROOT (A, IA, ROMOD, ROOIS, M, MNONRT, NONRT,

$c$ IMROMOD, NCO, DELTA, EPSILON, NCUR I

DIMENSIDN $A(51,3), I A(51,3), \operatorname{ROMOD}(50), \operatorname{ROOTS}(2,50), \operatorname{SR}(51,3), \operatorname{ISR}(51,3$ 1), SROMOD (50), SROOTS $(2,50)$, MNDNRT (50), NONRT (50), MSROMOD (50), 2NSONRT (49), MSNORT (49), MROMOD (50),D(2), R(2), B(49)

TYPE DOUBLE A,ROMOD,ROOTS,SR, SROMOD, SROOTS, $X, Y, T, W, Q$,

IWE, U, D, R, B, DCNEX

DO $23 \mathrm{I}=1, \mathrm{NCO}$

$J A=$ NONRT $(I)$

$I I=$ MNONRT (I)

$I 1=I 1 / 2$

If (I I) $1,1,2$

I I $I=1$

2 IF (ROMOO(JA)) $3,23,3$

$3 Q=R \cap M O D(J A)$

$0022 \mathrm{~J}=1, \mathrm{I} I$

300 CALL SUBRES (A, I A, NCUR, SR, I $S R, Q$ )

IF (NCUR-4) 4, 100,5

100 NSCUR $=2$

GO TO 101

4 NSCUR $=1$

$\mathrm{J} 2=1$

GO TO 6

5 NSCUR $=$ NCUR -3

$101 \mathrm{~J} 2=N S C U R$

$6 L L=N S C U R+1$

IF (NSCUR-1) 7,7,9

$7 \operatorname{IF}(S R(1,1)) \quad 8,10,8$

$8 X=\operatorname{SR}(1,1) \$[X=\operatorname{ISR}(1,1)$

$Y=\operatorname{SR}(2,1)$ \$ $\operatorname{I} Y=I S R(2,1)$

CALL UNSCALE $(X, I X)$

CALL UNSCALE $(Y, I Y)$

$S R O O T S(1,1)=-Y / X$

NSSCUR $=0$

GO TO 11

9 CALL ROOTSS (SR, ISR, NSCUR, M)

CALL REALROOT (SR, ISR, M, NSCUR, DELTA, EPSILON, SROMOD, MSROMOD,

INSONRT, MSNORT, NSCD, SROOTS)

IF $(J 2-N S C U R) \quad 10,10,11$

$10 \operatorname{SROOTS}(1, J 2)=0.0$

$11 \operatorname{SROOTS}(1, J 2)=\operatorname{SROOTS}(1, J 2) * \operatorname{ROMOD}(J A)$

$T=\operatorname{ROMOD}(\mathrm{JA})+\operatorname{ROMOD}(\mathrm{JA})$

IF (SROOTS $(1, \mathrm{~J} 2)-\mathrm{T}) 12,16,16$

$12 W=S R O O T S(1, J 2)$

$W E=R O M O D(J A) * R O M O D(J A)$

CALL TEST (A, IA, W, WE, NCUR, ROMOD (JA), EPSILON,K)

IF (K) $15,15,13$. 
13 ROOTS $(1, N(U R)=-W / 2.0$

$T=4.0 * W E$

$U=W * W$

$\mathrm{T}=\mathrm{T}-\mathrm{U}$

IF (T) $201,201,202$

$201 \mathrm{~T}=-\mathrm{T}$

$U=D S Q R T$ (T)

ROOTS $(1, N C U R)=R O O T S(1, N C U R)-U / 2.0$

$\operatorname{ROOTS}(1, N C U R-1)=-(h-U) / 2.0$

$\operatorname{ROOTS}(2, N C U R)=0.0$

$\operatorname{ROOTS}(2, N C U R-1)=0.0$

GO TO 204

202. $U=D S Q R T(T)$

203 ROOTS $(.2, N C U R)=U / 2.0$

ROOTS $(1, N C U R-1)=\operatorname{ROOTS}(1, N C U R)$

$204 \mathrm{D}(1)=W$

$D(2)=W E$

CALL QUAUIV (NCUR, $A, I A, R, D, B$ )

$J X=N C U R-1$

DO $14 J Y=1, J X$

$A(J Y, 1)=B(J Y)$

$I A(J Y, 1)=0$

CALL SCALE (AIJY,1), IA (JY,1))

14 CONTINUE

NCUR $=$ NCUR -2

GO TO 22

$15 W=-W$

CALL TEST (A, IA, W, WE, NCUR, ROMOD (JA), EPSILON,K)

IF (K) $16,16,13$

16 IF $(J 2-(N S C U R+1)) 23,17,19$

17 IF $(\mathrm{J} 2-1) 23,23,18$

$18 \mathrm{~J} 2=\mathrm{J} 2-1$

$\operatorname{SROOTS}(1, \sqrt{ } 2)=0.0$

GU IU 12

19 IF $(\operatorname{SROOTS}(1, J 2)-\operatorname{SROOTS}(1, \mathrm{~J} 2-1)) 20,2 \mathrm{i}, 20$

$20 \mathrm{~J} 2=\mathrm{J} 2-1$

GO TO 11

$21 \mathrm{~J} 2=\mathrm{J} 2-1$

GO TO 16

22 CONTINUE

23 CONTINUE

PETURN

END 


\section{f. Subroutine TEST}

(Tests roots for accuracy)

c SUBROUTINE TEST (A, IA,W,Q,N,ROMOD,EPSILON,K)

DIMENS ION $A(51,3), I A(51,3), B(3), I B(3), T(2), E(2), C(51)$

TYPE DOUBLE $A, B, W, X, Y, Z, C E P S I L, E, C, D I F, G, R O M O D$

$B(I)=0.0 \$ I X=0 \$ I W=0$

$I B(1)=0$

$B(2)=A(1,1)$

$I B(2)=1 A(1,1)$

DO. $2 \quad I=1, N$

$X=W \# B(2)$

$I X=I B(2)$

CALL SCALE $(X, I X)$

$Y=Q * B(1)$

$I Y=I B(1)$

CALL. SCALE $(Y, I Y)$

CALL ADD $(X, I X, Y, I Y, Z, I Z)$

CALL SUBTRACT $(A(1+1,1), I A(1+1,1), 2,12, B(3), 1 B(3))$

IF $(N-I) \quad 2,2,1$

$1 B(1)=B(2)$

$I B(1)=I B(2)$

$B(2)=B(3)$

$I B(2)=I B(3)$.

2 CONTINUE

3 KOUNT $=1$

CEPSIL =EPSILON

$T(1)=0.0 \$ T(2)=0.0$

$\mathrm{NI}=\mathrm{N}+\mathrm{I}$

$X=2.0$ EPSILON

$Y=X \# R O M O D$

$E(1)=R O M O D+Y$

$E(2)=R O M O D+C E P S I L * R O M O D$

DO 7 I $=1, N I$

IF $(A(I, 1)) \quad 4,5,5$

$4 C(I)=-A(I, I) \$ I C=I A(I, I)$

GO TO 6

$5 C(I)=A(I, 1) \$ I C=I A(I, I)$

6 CALL UNSCALE (C(1); iC)

$T(1)=I(1) * E(1)+C(I)$

$T(2)=T(2) * E(2)+C(I)$

7 CONTINUE

$D I F=T(1)-T(2)$

8 IF (Q) $18,9,18$

9 IF $(B(3)) 10,11,11$

$10 B(3)=-B(3)$

11 IF $(I B(3)-150) 100,100,12$

100 . IF $(I B(3)+150) 12,101,101$

101 CALL UNSCALE (B(3), IB (3))

IF $(D I F-B(3)) \quad 12,12,17$ 


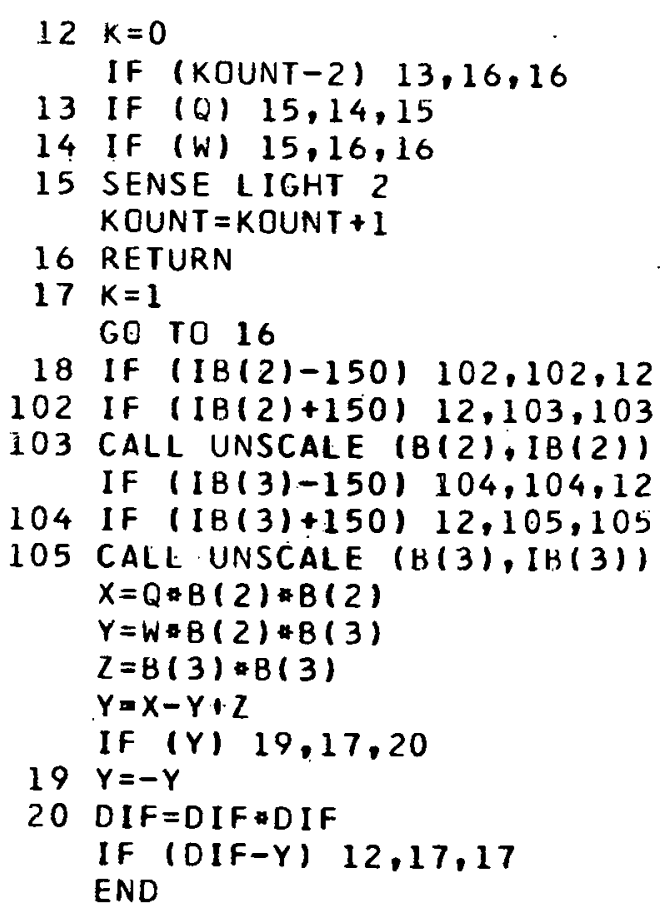




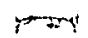

\title{
g. Subroutine SUBRES
}

(Computes reduced subresultant polynomial or, if $\mathrm{n}=4$, the subresultant polynomial)

C

\author{
SLBROUTINE. SUBRES (A, IA,N, SR, ISR, ROMOD)
}

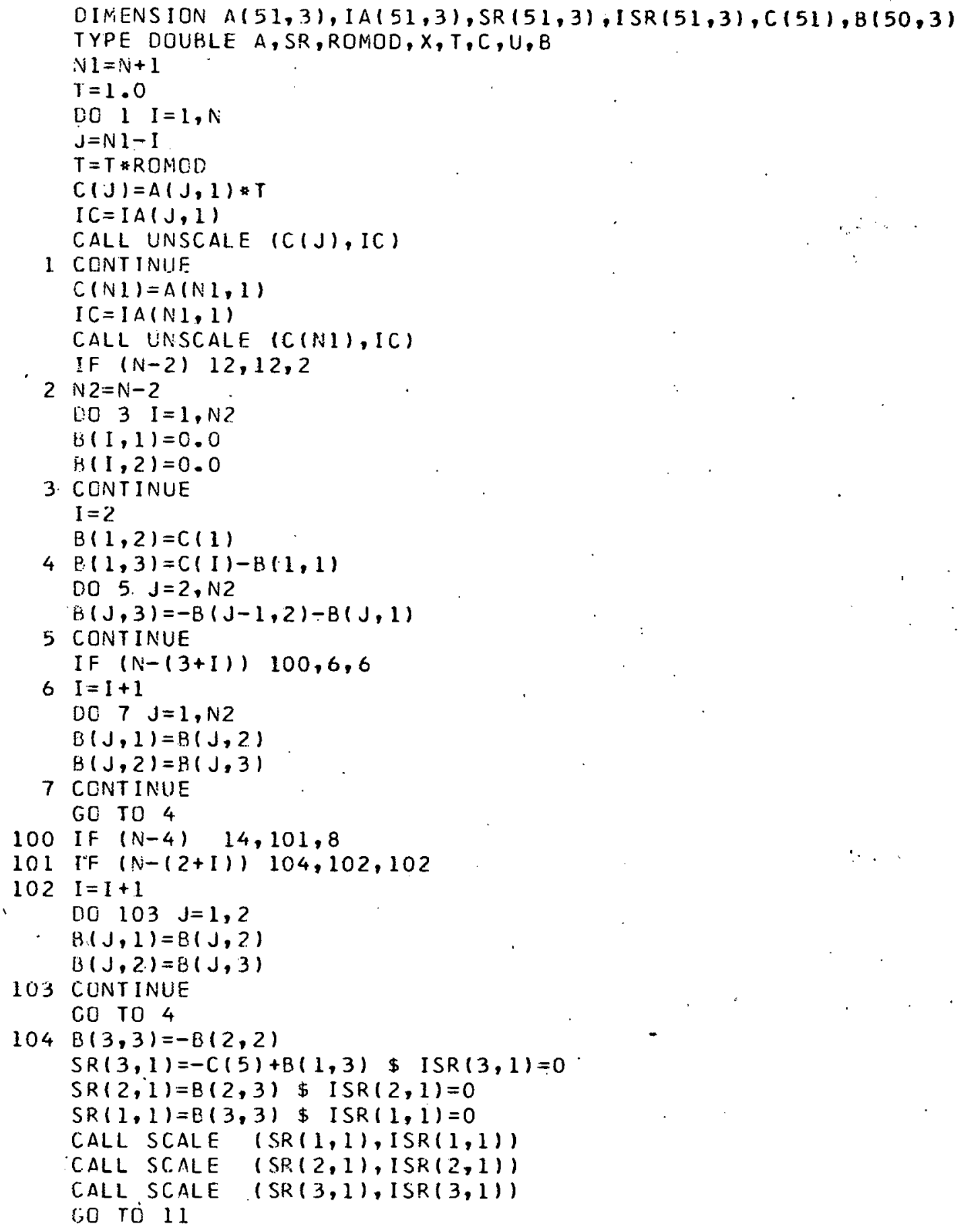


$8 S R(N 2,1)=C(N)-B(1,3) \& \operatorname{ISR}(N 2,1)=0$

R.: $:$

$S R(N 2-1,1)=-C(N 1)-P(2,3) \quad \$ \quad I S R(N 2-1,1)=0$

CALL SCALE (SR(N2,1),ISR(N2,1))

CALL SCALE (SR(N2-1,1),ISR(N2-1,1))

IF $(\mathrm{N} 2-2) \quad 11,11,9$

$90010 \mathrm{~J}=3, \mathrm{N2}$

$\mathrm{K}=\mathrm{N} 2+\mathrm{I}-\mathrm{J}$

$S R(K, 1)=-P(J, 3) \quad \$ I S R(K, 1)=0$

CALL SCALE $(S R(K, 1), \operatorname{ISR}(K, 1))$

10 CONTINUE

11 RETURN

$12 \operatorname{SR}(1,1)=C(1)$ क $\operatorname{ISR}(1,1)=0$

$S R(2,1)=-C(2) \$ \operatorname{ISR}(2,1)=0$

13 CALL SCALE (SR(1,1), ISR $(1,1)$

CALL SCALE $(\operatorname{SR}(2,1), \operatorname{ISR}(2,1))$

GO TO 11

$14 \operatorname{SR}(1,1)=-C(4)$

$S R(2,1)=C(-3)-C \cdot(1)$.

$\operatorname{ISR}(1 ; 1)=0$

$\operatorname{ISP}(2,1)=0$

GO TO 13

END 
h. Subroutine RECON

(Reconstructs the polynomial from the roots and the first coefficient)

c

SUBROUTINE RECUN (ROOTS, A,IA,D,N)

DIMENSION ROOTS $(2,50), D(51)$

TYPE COUBLE ROOTS,A,D,X,T,U

$X=A \$ I X=I A$

CALL UNSCALE $(X, I X)$

DO $1 I=1, N$

$D(I)=0.0$

1 CONTINUE

$D(N+1)=1.0$

$I=1$

$\mathrm{NL}=\mathrm{N}-1$

2 If (ROOTS $(2,1)) \quad 3,7,3$

$3 T=R O O T S(1,1) * \operatorname{ROOTS}(1,1)$

$U=\operatorname{ROOT} S(2, I) * \operatorname{ROUTS}(2, I)$

$T=T+U$

$U=2.0 \cdot \operatorname{RCOTS}(1, I)$

DC $5 \mathrm{~J}=1, \mathrm{NL}$

IF $(I+J-N) \quad 5,4,4$

$4 D(J)=D(J+2)+T * D(J)$

$D(J)=D(J)-U * D(J+1)$

5 CONTINUE

$D(N)=T * D(N)$

$D(N)=C(N)-U * D(N+1)$

$D(N+1)=T * D(N+1)$

$I=I+2$

6 If $(N-I) \quad 10,2,2$

7 DO $9 \mathrm{~J}=1, \mathrm{~N}$

If $(J+I-N) \quad 9,9,8$

$8 D(J)=C(J+1)-D(J) * R O O T S(I, I)$

9 CONTINUE

$D(N+1)=-D(N+1) \cdot R O O T S(1, I)$

$\mathrm{I}=\mathrm{I}+\mathrm{I}$

GO TO 6

$10 N S=N+1$

DO $11 I I=1$,NS

$D(I I)=D(I I) * x$

11 CONTINUE

RETURN

END 


\section{i. Subroutine QUADIV}

(Divides out quadratic factors)

c

$$
\text { SUBROUTINE QUADIV }(N, A, I A, R, D, B)
$$

DIMENSION $A(51,3), 1 A(51,3), R(2), D(2), B(49)$

TYPE DOUBLE $A, R, D, B, X N, Y N, A A$

$B(1)=A(1,1) \$ I B=I A(1,1)$

CALL UNSCALE $(B(1)$, IB)

If $(N-2), 4,4,1$

I $A A=A(2,1) \$ I A A=I A(2,1)$

CALL UNSCALE (AA, IAA)

$B(2)=A A-B(1) * D(1)$

If $(N-3) \quad 4,4,2$

$2 N T=N-1$

DO $3 \quad I=3, N T$

$X N=B(I-1): D(1)$

$Y N=B(I-2) * C(2)$

$A A=A(I, I) \$ I A A=I A(I, 1)$

CALL UNSCALE (AA, IAA)

$B(I)=A A-(X N+Y N)$

3 CONTINUE

$4 X N=B(N-1) * 0(1)$

$Y N=B(N-2) * D(2)$

$\triangle A=A(N, I) \$ I A A=I A(N, I)$

CALL UNSCALE (AA, IAA)

$R(I)=A A-(X N+Y N)$

$A A=A(N+1,1) \$ I A A=I A(N+1,1)$

CALL UNSCALE (AA, IAA)

$R(2)=A A-B(N-1) * D(2)$

RE TURN

END 
j. Subroutine DOUBLOG

(Computes double-precision log for numbers of the form $x$ times $64^{\mathrm{Ix}}$ )

C SUBROUTINE COUBLOG $(X, I X, Y, I Y)$

TYPE DOUBLE $X, Y, T$ $T=64.0$

IF $(x) 1,5,3$

1 WRITE $(61,2)$

2 FGRMAT 146 HOTHE LOG OF A NON-POSITIVE NUMBER IS REQUESTEDI

$5 Y=0.0$

I $Y=0$

GO TO 4

$3 Y=D L O G(X)+I X * D L O G(T)$

I $Y=0$

CALL SCALE $(Y, I Y)$

4 RETURN

END 
k. Subroutine DOUBLEXP

(Computes in double precision, $e^{t}$, where $t=x\left(64^{I x}\right)$ )

c

SUBROUTINE COUBLEXP $(X, I X, Z, I Z)$

TYPE DOUBLE $X, Y, Z$.

$Z=D E X P(X) \$ I Z=0$

IF (IX) $1,8,6$

$1 I=-I \times \$ I I=6 * I$

DO $4 \mathrm{~J}=1, \mathrm{II}$

$K=X M O D F(17,2)$

IF $(K) 2,3,2$

$2 \quad I Z=I Z-1$

$Z=64.0 * 2$

$3 \quad I Z=I Z / 2$

$Z=D S Q R T(Z)$

CALL SCALE $(Z, I Z)$

4 CONTINUE

5 RETURN

$6 I=6 * I X$

Do $7 \mathrm{~J}=1, \mathrm{I}$

$Z=2 * Z \$ 1 Z=I Z+I Z$

CALL SCALE $(Z, I Z)$

7 CONTINUE

GO TO 5

8 CALL SCALE $(Z, I Z)$

GO TO 5

END 


\section{Subroutine ADD}

(Adds numbers of the for $m x\left(64^{\mathrm{Ix}}\right)$ and $y\left(64^{\mathrm{Iy}}\right)$, where $x$ and $y$ are in double precision)

C

SUBROUTINE ADC $(x, I X, Y, I Y, Z, 1 Z)$

TYPE DOUBLE $X, Y, Z, A, B$

If $(X) \quad 3,1,3$

$1 Z=Y$

$I Z=I Y$

2 RETURN

3 IF $|Y| 5,4,5$

$4 Z=X$

$I Z=I X$

GO TO 2

5 ICIFF $=I X-I Y$

If (IDIFF) $6,7,7$

6 IA $=1 Y$

$A=Y$

$B=X$

IC IFF $=-$ ID I FF

GO TO 8

$7 \quad 1 A=I X$

$A=X$

$B=Y$

8 IF $(16-$ IDIFF $) 9,9,10$

$9 Z=A$

$I Z=I A$

GO TO 2

$100011 \mathrm{I}=1$, ICIFF

$B=B / 64.0$

11 CONTINUE

$Z=A+B$

$I Z=I A$

CALL SCALE $(Z, I L)$

GO TO 2

END 
m. Subroutine SUBTRACT

(Subtracts numbers of the for $\mathrm{m} x\left(64^{\mathrm{Ix}}\right)$ and $\mathrm{y}\left(64^{\mathrm{Iy}}\right)$ where $x$ and $y$ are in double precision)

C

$$
\text { SUBROUTINE SUBTRACT }(X, I X, Y, I Y, Z, I Z)
$$

TYPE DOUBLE $X, Y, Z, W$

$W=-Y$

CALL ADD $(X, I X, W, I Y, Z, I Z)$

RETURN

END 


\section{n. Subroutine SCALE}

(Scales double-precision numbers of the form $\mathrm{x}$ times 64 Ix so that $1 / 64 \leq 1|x| 1 \leq 64(x \neq 0))$

C

SUBROUTINE SCALE $(X, I X)$

TYPE DOUBLE $X, Y$

REC64 $=1.0164 .0$

If $(X) 1,11,2$

$1 y=-x$

60 I0 3

$2 \quad Y=X$

3 If $(64,0-Y) \quad 4,5,5$

$4 Y=Y / 64.0$

I $X=I X+1$

Go I0 3

5 If $(Y-R E C 64) \quad 6,7,7$

$6 Y=Y: 64.0$

I $X=I X-1$

60 TO 5

7 If $(X) \quad 8,9,9$

$8 x=-Y$

GO TO 10

$9 \quad X=Y$

10 RETURN

11 I $X=0$

GO TO 10

END 


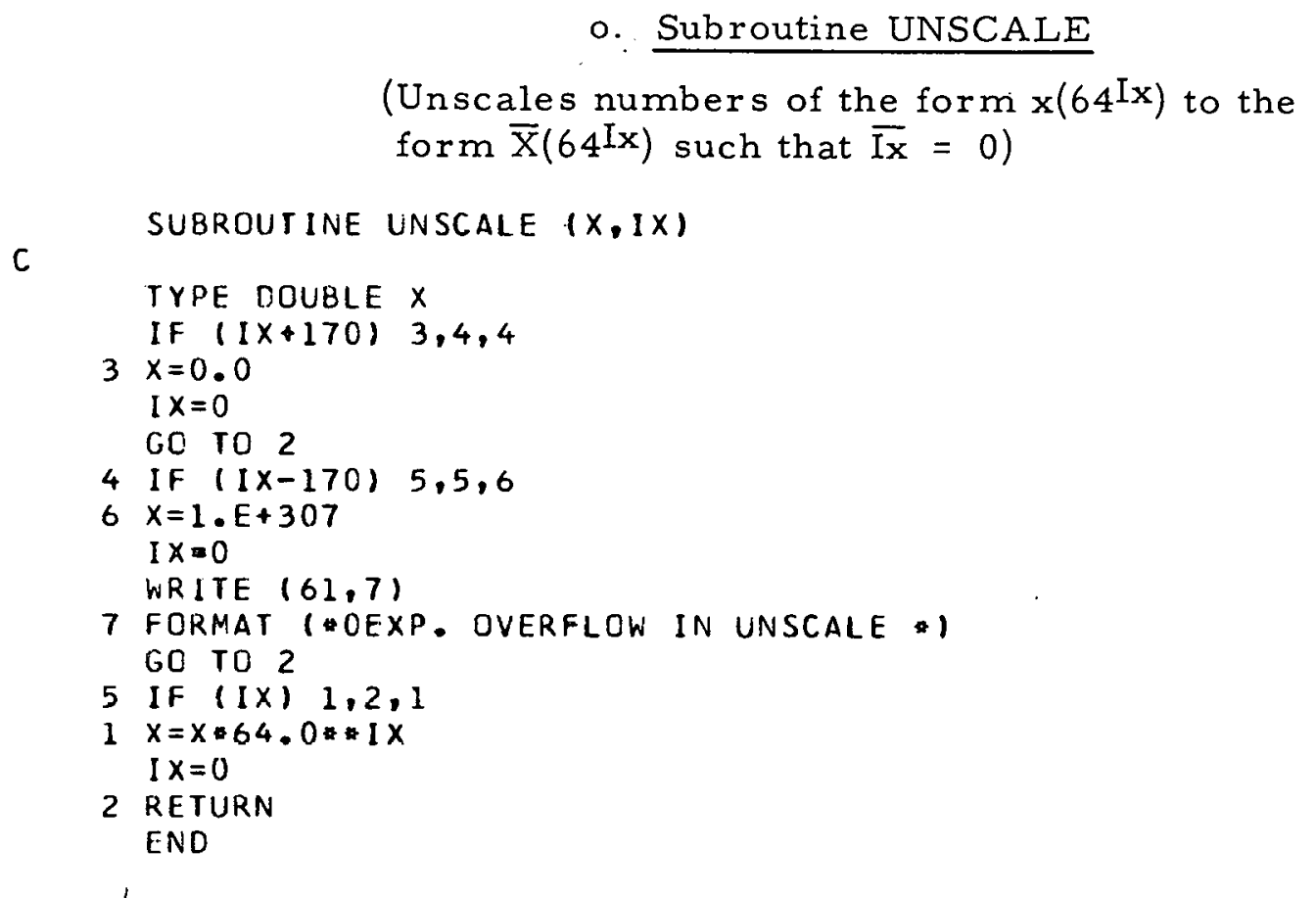




\section{APPENDIX C}

Operating. Instructions

1. Operating Instructions for IBM-704

a. Input Information

The following cards are required.

1) Title card. Format (72H).

Column I should be a "l" to restore the printer. The remainder of the card through column 72 contains the title which will head the output:

2) The second card is transcribed either in standard form or in. special form. The standard form should normally prove satisfactory, although occasionally the results may be insufficiently accurate for some polynomials or unnecessarily precise for others.

(a) Standard Form

NDEGRE. Format (I6)

NDEGRE is the degree of the polynomial. If NDEGRE is $\leq 0$ the program returns control to the monitor.

Standard settings are given to other program parameters. (See b below.)

(b) Special Form

NDEGRE, M, MMAX, DELTA, EPSIL. Förmat (3I6, 2E12.6)

NDEGRE is the degree of the polynomial.

$M$ is the minimum number of root squarings to be performed. The standard setting is $M=10$.

MMAX is the maximum number of root squarings allowed. The standard setting is MMAX $=15$.

DELTA is the pivotal bound. The standard setting is $10^{-4}$. EPSIL is the tolerable relative error in the modulus of a root. The standard setting is $10^{-6}$.

For low-degree polynomials (up to 6), the user can decrease $M$ and MMAX from the standard settings while using the standard settings for DELTA and EPSIL. For difficult polynomials, the user should increase $M$ and MMAX and decrease EPSIL and DELTA from their standard settings.

3) IPI, IPंO. Format (2I6).

IPI $=\left\{\begin{array}{l}2 \rightarrow \text { double-precision coefficient input. } \\ 1 \rightarrow \text { single-precision coefficient input. }\end{array}\right.$ 
IPO $=\left\{\begin{array}{l}2 \rightarrow \text { double-precision output. } \\ 1 \rightarrow \text { single-precision output. }\end{array}\right.$

4) NDEGRE + 1 cards containing the coefficients are required. If the polynomial is

$$
P(x)=\sum_{i=0}^{N D E G R E} a_{i} x^{N D E G R E-i},
$$

then the $j^{\text {th }}$ card must contain $a_{j-1}$.

If $\operatorname{IPI}=1$, the coefficient is read with format (E12.6).

If TPT = 2, the coefficient is read with format (6I6) and is transcribed as follows:

$$
\text { Let } a_{j-1}=b_{1} b_{2} b_{3} b_{4} \ldots b_{16} b_{17} b_{18} b_{19} b_{20} \times 10^{k} \text {, }
$$

where $0 \leq b_{i} \leq 9$, i.e., a representation with up to 20 significant digits appearing to the left of the decimal point and none to the right. Then the six right-adjusted integers entered on the $\mathrm{j}^{\text {th }}$ card are, respectively:

$$
b_{1} b_{2} b_{3} b_{4}, b_{5} b_{6} b_{7} b_{8}, b_{9} b_{10} b_{11} b_{12}, b_{13} b_{14} b_{15} b_{16}, b_{17} b_{18} b_{19} b_{20}, k \text {. }
$$

If the coefficient is negative, negative signs prefix each of the first five entries; $k$ is negative if the coefficient is not an integer.

Further sets of data including title cards may follow and consecutive cases run.

b. Possible Output

For each polynomial equation solved, the following is printed:

1. The title.

2. NDEGRE, M, DELTA, EPSIL (EPSIL is designated EPSILON).

3. The input coefficients of defined (via IPI) precision.

4. The roots of the polynomial with specified (via IPO) precision.

5. The coefficients of the polynomial as reconstructed from the roots and leading coefficient.

c. Additional Information

If any roots cannot be found, an appropriate message is printed, and reconstruction of the coefficients is not attempted. 
2. Operating Instructions for CDC-3600

The following set of cards must be presented in order for each polynomial to be solved.

a. Title card. Format (10A8).

All 80. columns may be used.

b. DEGREE, M, MMAX, DELTA, EPSILON. Format (3I6, 2E12.4).

If $M=0$, the standard setting is made for $M$, MMAX, DELTA and EPSILON.

DEGREE = degree of the polynomial.

$M=$ number of root squarings desired.

MMAX = maximum number of root squarings allowed.

DELTA = the pivotal coefficient bound.

EPSILON = the acceptance tolerance allowed on roots.

The general user is advised to use the standard setting; hence, only DEGREE will occur on this card.

c. IPI, IPO. Format (2I6).

IPI $=\left\{\begin{aligned} 2 & \rightarrow \text { double-precision coefficient input. } \\ 1 & \rightarrow \text { single-precision coefficient input. }\end{aligned}\right.$

IPO $=\left\{\begin{array}{l}2 \rightarrow \text { double-precision output. } \\ 1 \rightarrow \text { single-precision output. }\end{array}\right.$

(In any case, internal computations are done in double precision.)

d. $A_{i} \cdot$ Format $\left\{\begin{array}{l}E 18.19 \text { if IPI }=1 \\ D 36.25 \text { if IPI }=2\end{array}\right\}$

These are the coefficients of the polynomial

$$
\sum_{i=0}^{n} A_{i} x^{n-i}
$$

and are given one to a card beginning with $A_{0}$, on through $A_{n}$. 


\section{ACKNOWLEDGMENTS}

The authors wish to thank William L. Hafner, Jr., for his help in the final debugging of the CDC -3600 code and for his careful preparing and solving of numerous test polynomials, a few of which are discussed in Appendix A.

\section{REFERENCES}

1. E. H. Bareiss, Resultant Procedure and the Mechanization of the Graeffe Process, Journal ACM 7, 1960, S. 346-386.

2. E. H. Bareiss and M. A. Fisherkeller, Resultant Procedure, A Method for Finding the Zeros of Real Polynomials, ANL-5997 (1959).

3. W. Barth, Praktisches Vorgchen und Fehlerabschätzung beim Graeffe-Verfahren. Dissertation, Darnstadt (1963).

4. W. Börsch-Supan, A-posteriori Error Bounds for the Zeros of Polynomials, Num. Math. (im Druck).

5. F. B. Hildebrand, Introduction to Numerical Analysis, McGraw-Hill Book Company, Inc., New York (1956).

6. A. Ralston, A First Course in Numerical Analysis, McGraw-Hill Book Company, Inc., New York (1965).

7. N. P. Salikov, A Modification of Lobatchevsky's Method for Calculating the Moduli of the Roots of an Algehraic Equaliun (Russian), Z. Vycisl. Mat. i Mul. Fiz. 3 (1963), 54-70.

8. J. H. Wilkinson, The Evaluation of the Zeros of Ill-conditioned Polynomials, Num. Math. 1 , 1959, S. 150-180.

9. J. H. Wilkinson, Error Analysis of Floating-point Computation, Num. Math. 2, 1960, S. 319-340.

10. J. H. Wilkinson, Rounding Errors in Algebraic Processes, Her Majesty's Stationery Office, London, 1963.

11. NR NPRE Double Precision Arithmetic (FORTRAN) SHARE Dist. 1122. 